
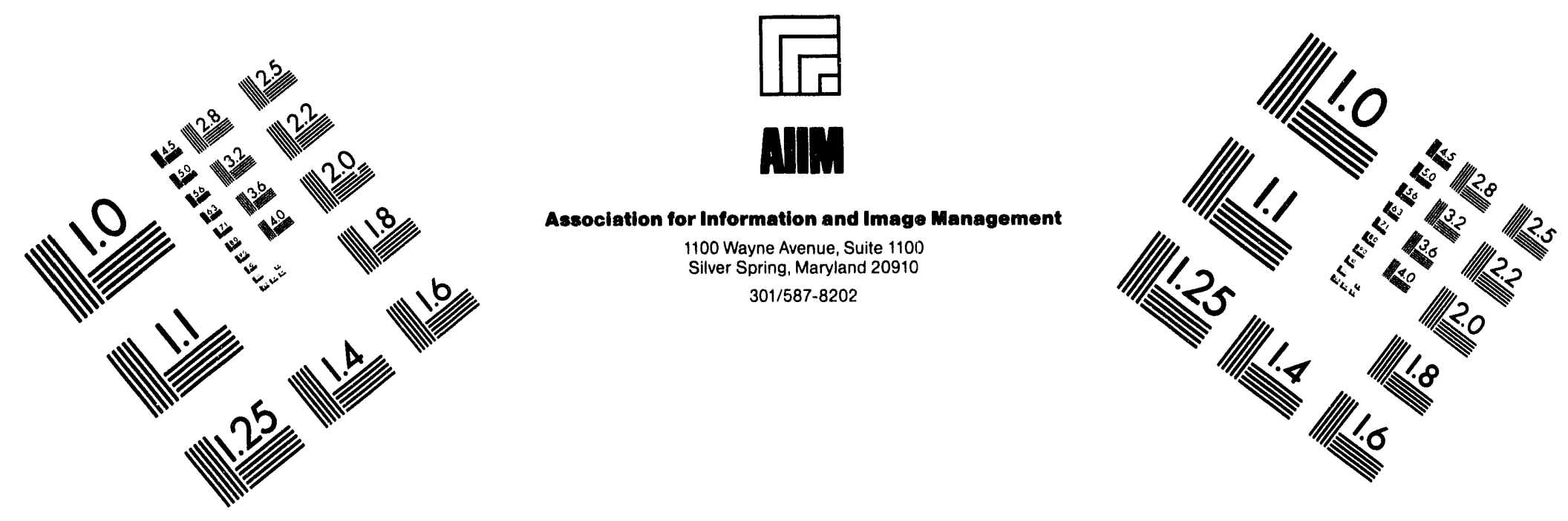

\title{
Centimeter
}

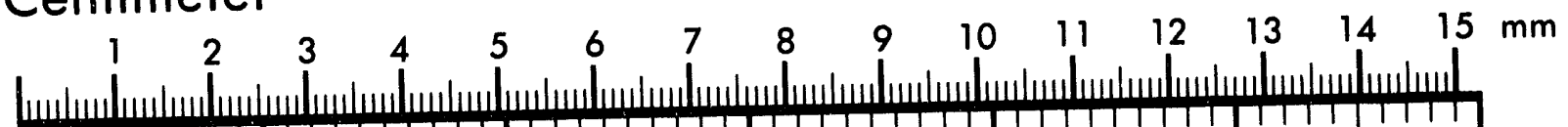

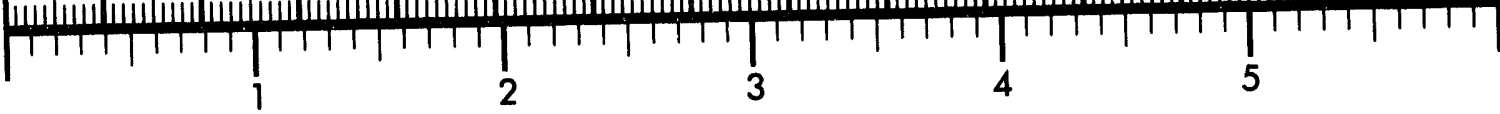
Inches
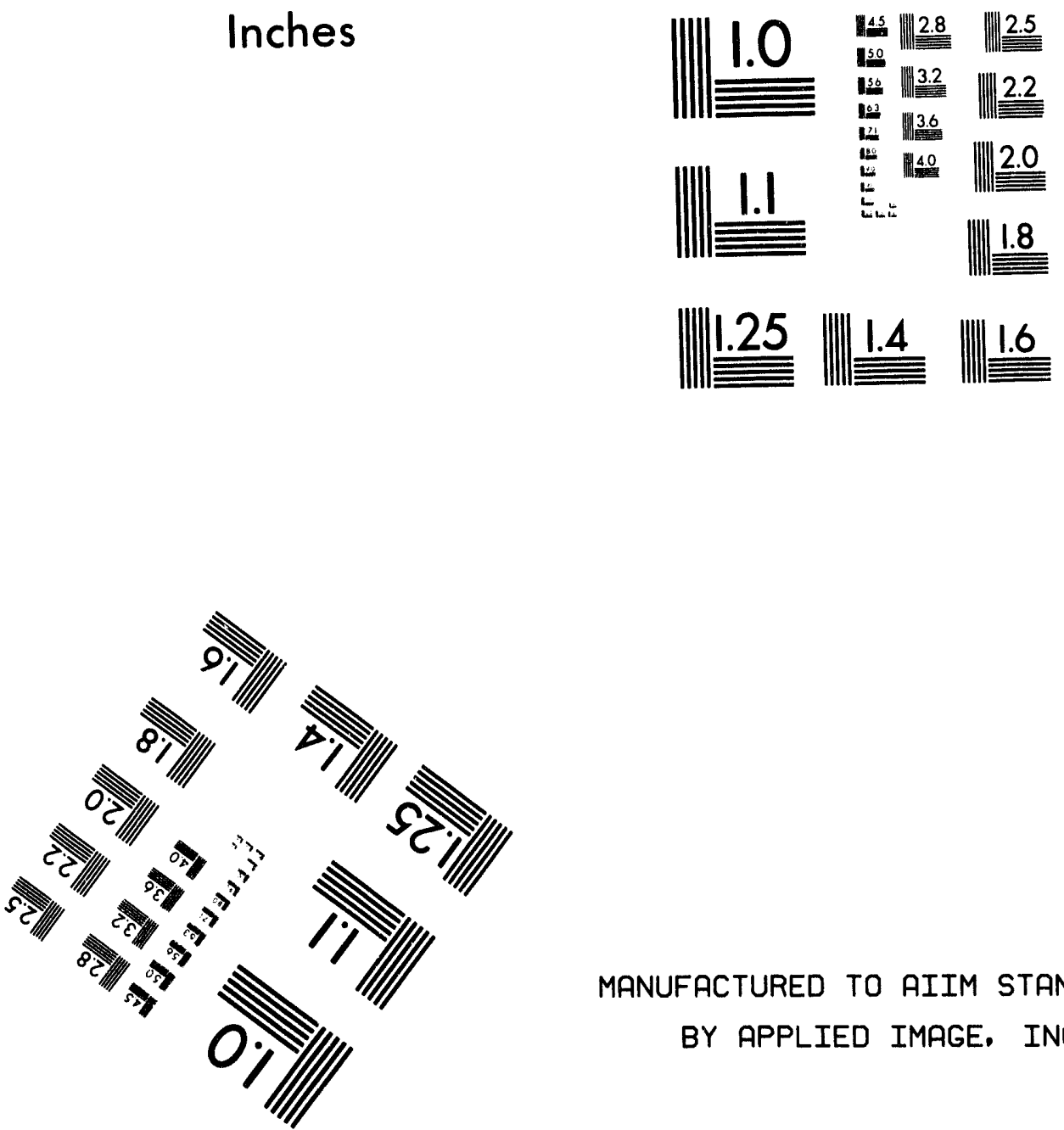

MANUFACTURED TO AIIM STANDARDS

BY APPLIED IMAGE. INC.

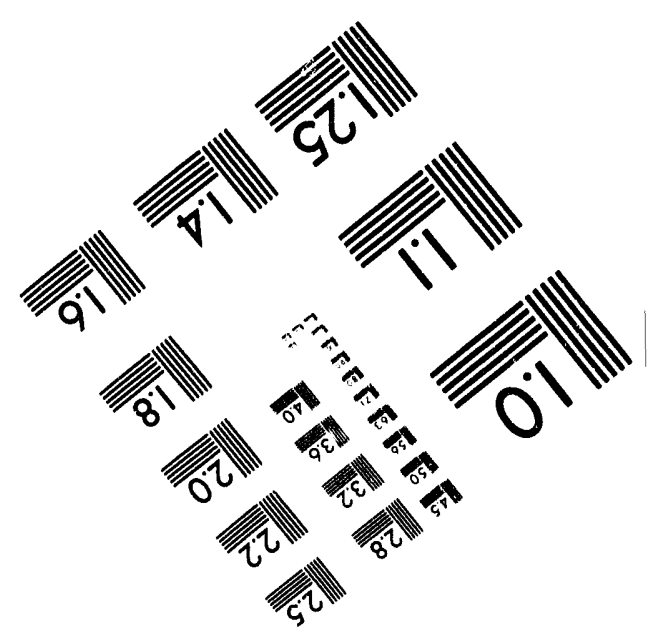




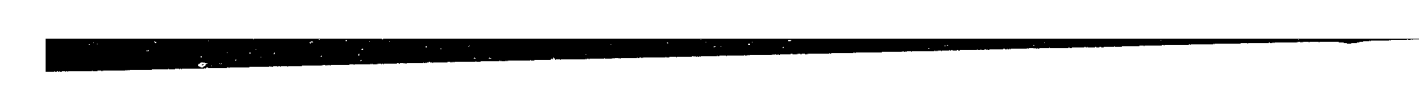
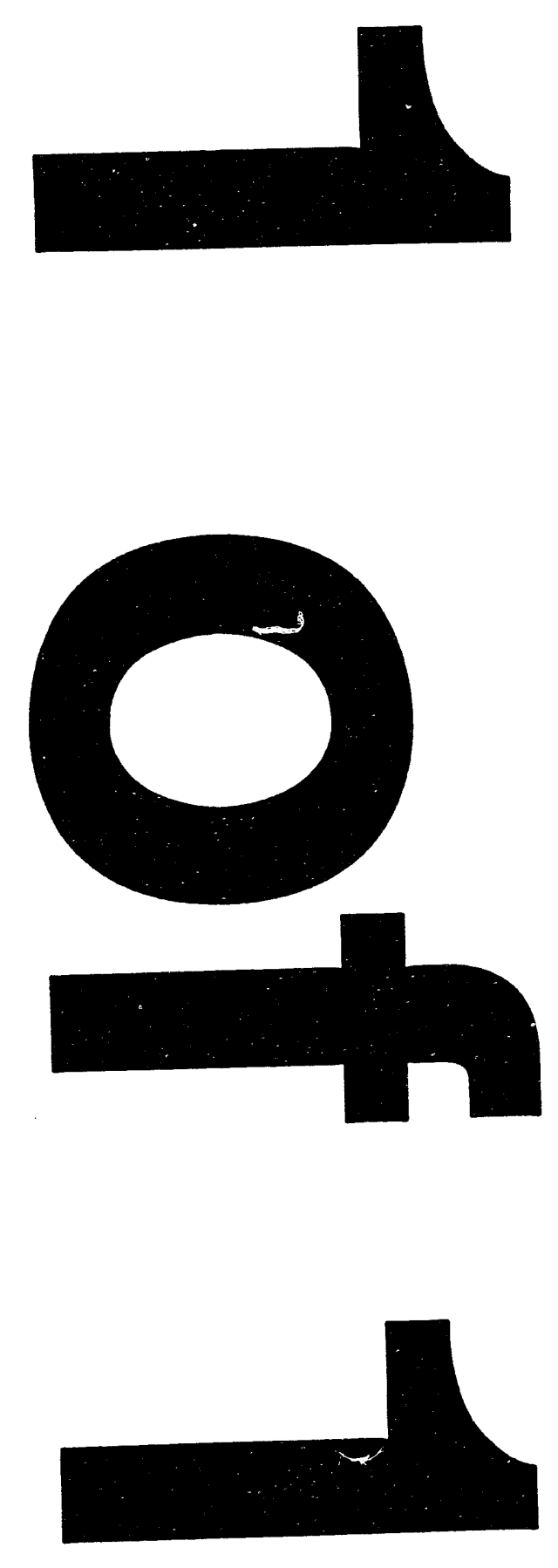


\section{Numerical Modeling of Ductile Tearing Effects on Cleavage Fracture Toughness}

Prepared by

R. H. Dodds, Jr., M. Tang, University of Illinois

T. L. Anderson, Texas A\&M University

University of Illinois

Department of Civil Engineering

205 North Mathews Ave.

Urbana, IL 61801

Texas A\&M University

Department of Mechanical Engineering

College Station, TX 77848

Under contract to:

Naval Surface Warfare Center

Carderock Division

Code 614

Annapolis, MD 21402-5067

\section{Prepared for}

Division of Engineering

Office of Nuclear Regulatory Research

U.S. Nuclear Regulatory Commission

Washington, DC 20555-0001

NRC FIN J6036 


\begin{abstract}
Experimental studies demonstrate a significant effect of specimen size, $a / \mathrm{W}$ ratio and prior ductile tearing on cleavage fracture toughness values $\left(J_{c}\right)$ measured in the ductile-to-brittle transition region of ferritic materials. In the lower-transition region, cleavage fracture often occurs under conditions of large-scale yielding but without prior ductile crack extension. The increased toughness develops when plastic zones formed at the crack tip interact with nearby specimen surfaces which relaxes crack-tip constraint (stress triaxiality). In the mid-to-upper transition region, small amounts of ductile crack extension (often $<1-2 \mathrm{~mm}$ ) routinely precede termination of the $J-\Delta a$ curve by brittle fracture. Large-scale yielding, coupled with small amounts of ductile tearing, magnifies the impact of small variations in microscale material properties on the macroscopic fracture toughness which contributes to the large amount scatter observed in measured $J_{c}$-values.

Previous work by the authors described a micromechanics fracture model to correct measured $J_{c}$-values for the mechanistic effects of large-scale yielding. This new work extends the model to also include the influence of ductile crack extension prior to cleavage. Ductile crack extensions of 10-15 $\times$ the crack-tip opening displacement at initiation are considered in plane-strain, finite element computations. The finite element results demonstrate a significant elevation in crack-tip constraint due to macroscopic "sharpening" of the extending tip relative to the blunt tip at initiation of growth. However, this effect is offset partially by the additional plastic deformation associated with the increased applied $J$ required to grow the crack. The initial $a / W$ ratio, tearing modulus, strain hardening exponent and specimen size interact in a complex manner to define the evolving near-tip conditions for cleavage fracture. The paper explores development of the new model, provides necessary graphs and procedures for its application and demonstrates the effects of the model on fracture data sets for two pressure vessel steels (A533B and A515).
\end{abstract}




\section{Contents}

Section No.

Page

Abstract

iii

List of Figures $\ldots \ldots \ldots \ldots \ldots \ldots \ldots \ldots \ldots \ldots \ldots \ldots \ldots \ldots \ldots \ldots$, vi

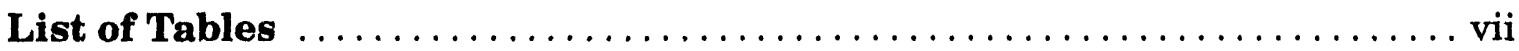

List of Prior Reports $\ldots \ldots \ldots \ldots \ldots \ldots \ldots \ldots \ldots \ldots \ldots \ldots \ldots \ldots \ldots$ viii

Acknowledgements $\ldots \ldots \ldots \ldots \ldots \ldots \ldots \ldots \ldots \ldots \ldots \ldots \ldots \ldots \ldots$

1. INTRODUCTION $\ldots \ldots \ldots \ldots \ldots \ldots \ldots \ldots \ldots \ldots \ldots \ldots \ldots \ldots \ldots \ldots$

2. MICROMECHANICAL CONSTRAINT CORRECTIONS $\ldots \ldots \ldots \ldots 2$

2.1 Transgranular Cleavage Mechanism $\ldots \ldots \ldots \ldots \ldots \ldots \ldots \ldots 2$

2.2 Constraint Corrections ................................. 4

2.3 Application of Constraint Corrections in Fracture Testing ......... 3

3.4 Extension to Include Effects of Ductile Tearing ............... 6

3. NUTMERICAL MODELS FOR GROWTH ANALYSES $\ldots \ldots \ldots \ldots \ldots 8$

3.1 Crack Growth Parameters $\ldots \ldots \ldots \ldots \ldots \ldots \ldots \ldots \ldots \ldots$

$3.2 J$-Values During Crack Growth $\ldots \ldots \ldots \ldots \ldots \ldots \ldots \ldots \ldots \ldots$

4. GROWTH EFFECTS ON CRACK-TIP FIELDS $\ldots \ldots \ldots \ldots \ldots \ldots, 11$

4.1 Crack Opening Profiles $\ldots \ldots \ldots \ldots \ldots \ldots \ldots \ldots \ldots \ldots \ldots \ldots \ldots \ldots$

4.2 Crack Opening Stresses on Remaining Ligament ............. 11

4.3 Principal Stress Contours $\ldots \ldots \ldots \ldots \ldots \ldots \ldots \ldots \ldots \ldots \ldots \ldots$

5. TEARING EFFECTS ON CONSTRAIN $\boldsymbol{\Gamma}$ MODEL $\ldots \ldots \ldots \ldots \ldots \ldots$

$5.1 \quad$ Normalizing $J_{I c}$ Effects $\ldots \ldots \ldots \ldots \ldots \ldots \ldots \ldots \ldots \ldots \ldots \ldots$

5.2 Application of Constraint Model Including Crack Growth ......... 24

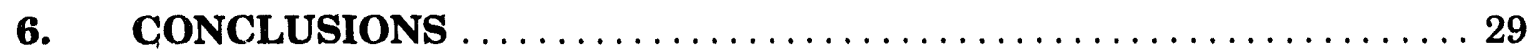

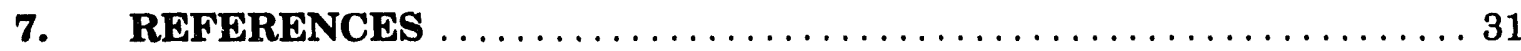




\section{LIST OF FIGURES}

Figure No.

Page

1 Cleavage constraint models for stationary cracks in SE(B) specimens with $a / W=0.1,0.5 ; n=5,10 ; E / \sigma_{0}=500$; using contour areas for $\sigma_{1} / \sigma_{0}=2.7 \ldots \ldots 5$

2 Schematic illustration of growth effects on constraint correction model $\ldots . .7$

3 Schematic illustrating construction of principal stress envelope for growing cracks. . . . . . . . . . . . . . . . . . . . . . . . 8

4 Finite element models for $\mathrm{SE}(\mathrm{B})$ specimens $\ldots \ldots \ldots \ldots \ldots \ldots \ldots \ldots$

$5 \mathrm{~J}$-integral variation over domain rings for both stationary and growing

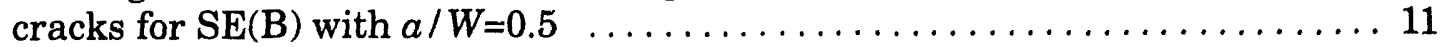

6 Opening profiles for stationary and growing cracks for shallow and

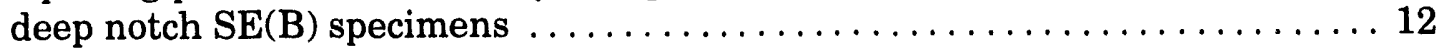

7 Effects of growth on crack opening stress in SE(B) specimens. For each $a / W$, growing cracks and stationary cracks are loaded to the same $J \ldots \ldots \ldots \ldots 14$

8 Effects of crack growth on the instantaneous principal stress contours in $\mathrm{SE}(\mathrm{B})$ specimens. For each $a / W$, growing cracks and stationary cracks

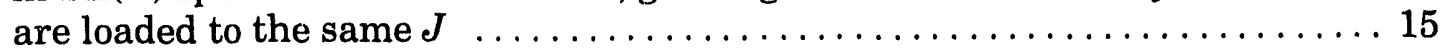

9 Effects of principal stress ratio and instantaneous vs. cumulative areas on $J_{0}$ for a shallow-notched $\mathrm{SE}(\mathrm{B})$ specimen $(a / W=0.1) \ldots \ldots \ldots \ldots \ldots \ldots$

10 Effects of principal stress ratio and instantaneous vs. cumulative areas on $J_{0}$ for a deep-notched $\mathrm{SE}(\mathrm{B})$ specimen $(a / W=0.5) \ldots \ldots \ldots \ldots \ldots \ldots$

11 Comparison of constraint corrections for growth based on areas enclosed within instantaneous and cumulative principal stress contours for $\mathrm{SE}(\mathrm{B})$ specimens $\left(T_{J}=40, \sigma_{1} / \sigma_{0}=2.7\right)$

12 Development of approximate normalization scheme to minimize dependence of growth constraint model on absolute values of $J_{I c} \ldots \ldots \ldots 21$

13 Gradients $(m)$ for stationary constraint models of SE(B) specimens $\left(a / W=0.1,0.5 ; n=5,10 ; E / \sigma_{0}=500\right)$

14 Growth portion of constraint model normalized to reference point on stationary crack solution for $\mathrm{SE}(\mathrm{B})(a / W=0.1 ; n=5,10)$

15 Growth portion of constraint model normalized to reference point on stationary crack solution for $\mathrm{SE}(\mathrm{B})(a / \mathrm{W}=0.5 ; n=5,10) \ldots \ldots \ldots \ldots \ldots \ldots$ 
16 Growth portion of constraint scaling model normalized to reference point on stationary crack solution for $\mathrm{SE}(\mathrm{B})(a / W=0.1 ; n=5$, 10 , high tearing modulus).

17 Experimental $J_{R}-\Delta a$ curves and three-parameter Weibull distribution for A533B with corrections for effects of crack growth and large-scale yielding

18 Experimental $J_{R}-\Delta a$ curves and three-parameter Weibull distribution for A515 with corrections for effects of crack growth and

large-scale yielding

\section{LIST OF TABLES}

Table No.

Page

1 Values of $J_{I c}$ and $T_{J}$ obtained by fitting experimental toughness values 27 


\section{PRIOR REPORTS}

Prior reports in this series are listed below:

1. J.A. Joyce, "Application of the Key Curve Method to Determining $J-R$ Curves for A533B Steel," NUREG/CR-1290, U.S. Nuclear Regulatory Commission, Washington, DC (January 1980).

2. J.P. Gudas, M.G. Vassilaros, J.A. Joyce, D.A. Davis, and D.R. Anderson, "Summary of Recent Investigations of Compact Specimen Geometry Effects on the $J_{I}-R$ Curve of High Strength Steels," NUREG/CR-1813, U.S. Nuclear Regulatory Commission, Washington, DC (November 1980).

3. J.A. Joyce, "Static and Dynamic J-R Curve Testing of A533B Steel Using the Key Curve Analysis Technique," NUREG/CR-2274, U.S. Nuclear Regulatory Commission, Washington, DC (July 1981).

4. J.A. Joyce, "Instability Testing of Compact and Pipe Specimens Utilizing a Test System Made Compliant by Computer Control," NUREG/CR-2257, U.S. Nuclear Regulatory Commission, Washington, DC (March 1982).

5. M.G. Vassilaros, J.P. Gudas, and J.A. Joyce, "Experimental Investigation of Tearing Instability Phenomena for Structural Materials," NUREG/CR-2570, Rev. 1, U.S. Nuclear Regulatory Commission, Washington, DC (August 1982).

6. Davis, D.A., Vassilaros, M.G., and Gudas, J.P., "Specimen Geometry and Extended Crack Growth Effects on $J_{I}-R$ Curve Characteristics for HY-130 and ASTM A533B

Steels," USNRC Report NUREG/CR-3089, U.S. Nuclear Regulatory Commission, Washington, DC (November 1982).

7. Vassilaros, M.G. et al., "J-Integral Tearing Instability for 8-Inch Diameter ASTM A106 Steel Pipe." USNRC Report NUREG/CR- 3740, U.S. Nuclear Regulatory Commission, Washington, DC (March 1984).

8. J.A. Joyce, "Development and Verification of Conditions for Ductile Tearing Instability and Arrest," NUREG/CR-4528, U.S. Nuclear Regulatory Commission, Washington, DC (February 1986).

9. Hays, R.A., Vassilaros, M.G., and Gudas, J.P., "Fracture Analysis of Welded Type 304 Stainless Steel Pipe," USNRC Report NUREG/CR-4538 Vol. 1, U.S. Nuclear Regulatory Commission, Washington, DC (February 1986).

10. Link, R.E., and Hays, R.A., "Investigation of Tearing Instability Phenomena in ASTM A106 Steel," USNRC Report NUREG/CR-4539, U.S. Nuclear Regulatory Commission, Washington, DC (February 1986).

11. Hackett, E.M., Kirk, M.T., and Hays, R.A., "An Evaluation of J-R Curve Testing of Nuclear Piping Materials Using the Direct Current Potential Drop Technique," USNRC Report NUREG/CR-4540, U.S. Nuclear Regulatory Commission, Washington, DC (June 1986).

12. J.A. Joyce and E.M. Hackett, "Application of the Key Curve and Multispecimen Techniques to Dynamic J-R Curve Testing of Alloy Steel, "NUREG/CR-4579, U.S. Nuclear Regulatory Commission, Washington, DC (April 1986).

13. J.A. Joyce and C.S. Schneider, "Application of Alternating Current Potential Difference to Crack Length Measurement During Rapid Loading," NUREG/CR-4699, U.S. Nuclear Regulatory Commission, Washington, DC (August 1986).

14. J.A. Joyce and E.M. Hackett, "Development of an Analytic Key Curve Approach to Drop Tower J-R Curve Measurement," NUREG/CR-4782, U.S. Nuclear Regulatory Commission, Washington, DC (December 1986). 
15. J.A. Joyce and E.M. Hackett, "Transition Range Drop Tower J-R Curve Testing of A106 Steel," NUREG/CR-4818, U.S. Nuclear Regulatory Commission, Washington, DC (February 1987).

16. J.A. Joyce "Ductile to Brittle Toughness Transition Characterization of A533B Steel," NUREG/CR-5142, U.S. Nuclear Regulatory Commission, Washington, DC (June 1988).

17. J.A. Joyce, D.A. Davis, E.M. Hackett, and R.A. Hays, "Application of the J-Integral to Cases of Large Crack Extension," NUREG/CR-5143, U.S. Nuclear Regulatory Commission, Washington, DC (February 1989).

18. J.A. Joyce and E. M. Hackett, "Development of an Engineering Definition of the Extent of J Singularity Controlled Crack Growth," NUREG/CR-5238, U.S. Nuclear Regulatory Commission, Washington, DC (May 1989).

19. J.A. Joyce and E.M. Hackett, "Extension and Extrapolation of $J-R$ Curves and Their Application to the Low Upper ShelfToughness Issue," NUREG/CR-5577, U.S. Nuclear Regulatory Commission, Washington, DC (March 1991).

20. J.A. Joyce, E.M. Hackett, and C. Roe, "Comparison of $J_{I c}$ and J-R Curves for Short Crack and Tensiley Loaded Specimen Geometries of a High Strength Structural Steel," NUREG/CR-5879, U.S. Nuclear Regulatory Commission, Washington, DC (November 1992).

21. O'Dowd, N.P. and Shih, C.F., "Two-Parameter Fracture Mechanics: Theory and Applications," NUREG/CR-5958, U.S. Nuclear Regulatory Commission, Washington, DC (February 1993).

22. Kirk, M.T. and Dodds, R.H., Jr., "J and CTOD Estimation Equations for Shallow Cracks in Single Edge Notch Bend Specimens," NUREG/CR-5969, U.S. Nuclear Regulatory Commission, Washington, DC (July 1993).

23. Kirk, M.T. and Dodds, R.H., Jr., "Approximate Techniques for Predicting Size Effects on Cleavage Fracture Toughness (JC)," NUREG/CR-5970, U.S. Nuclear Regulatory Commission, Washington, DC (July 1993).

24. Dodds, R.H., Jr., Shih, C.F., and Anderson, T.L., "Continuum and Micromechanics Treatment of Constraint in Fracture,” NUREG/CR-5971, U.S. Nuclear Regulatory Commission, Washington, DC (July 1993).

25. Joyce, J.A. and Link, R.E., "The Effect of Electric Discharge Machined Notches on the Fracture Toughness of Several Structural Alloys," NUREG/CR-5981, U.S. Nuclear Regulatory Commission, Washington, DC (September 1993).

26. Joyce, J.A. and Link, R.E., "Effects of Tensile Loading on Upper Shelf Fracture Toughness," NUREG/CR-5981, U.S. Nuclear Regulatory Commission, Washington, D.C. (in press).

27. Dodds, R.H., Jr., Tang, M. and Anderson, T.L., "Numerical Modeling of Ductile Tearing Effects on Cleavage Fracture Toughness," NUREG/CR-6162, U.S. Nuclear Regulatory Commission, Washington, D.C. (in press).

28. Koppenhoefer, K.C., Dodds, R.H., Jr., and Kirk, M.T., "Size and Deformation Limits to Maintain Constraint in $K_{I c}$ and $J_{c}$ Testing of Bend Specimens," NUREG/ CR-6191, U.S. Nuclear Regulatory Commission, Washington, D.C. (in press).

29. Tang, M., Dodds, R.H., Jr., and Anderson, T.L., "Effects of Ductile Crack Growth on Constraint Models for Cleavage Fracture," NUREG/CR-6199, U.S. Nuclear Regulatory Commission, Washington, D.C. (in press). 


\section{ACKNOWLEDGEMENTS}

This investigation was supported by grants principally from the Nuclear Regulatory Commission with additional support from Code 614, Annapolis Detachment, Carderock Division of the Naval Surface Warfare Center. Computations were performed on the Department of Civil Engineering HP/Apollo workstation network made possible, in part, by grants from the Hewlett-Packard Company.

The authors are pleased to acknowledge fruitful discussions with Dr. Kim Wallin and Prof. C. Fong Shih. 


\section{Introduction}

Experimental studies consistently reveal large scatter in the measured values of cleavage fracture toughness for ferritic steels tested in the ductile-to-brittle temperature transition region [see for example: 11, 12, 17, 27, 29, 33-35]. Moreover, data sets of seemingly identical specimens frequently show a mix of cleavage fractures with and without small amounts of prior stable tearing; fracture toughness values for specimens with prior growth often are significantly larger than toughness values for specimens without growth. The large amount of scatter, coupled with specimens that exhibit tearing prior to cleavage and yet others that show no tearing, greatly complicates the interpretation of toughness data to define meaningful values for application in fracture assessments of structures.

Scatter in fracture toughness values $\left(J_{c}\right)$ observed in the transition region arises from the complex interplay between the mechanistic effects of crack-tip constraint (stress triaxiality) and the stochastic variability of cleavage resistance at the microstructural level. Once the conditions of small-scale yielding no longer apply, interaction of crack-tip plastic zones with overall plastic deformation of the test specimen creates a highly nonlinear relationship between $J$ and near-tip stress triaxiality. For specimens experiencing significant levels of plastic deformation, large increases of $J$ must be imposed to produce increases in the near-tip stress fields. This phenomenon magnifies the impact of small variations in the microstructural cleavage resistance, and contributes a large measure of the scatter observed in fracture data. Dodds and Anderson [3, 7] proposed a stressed-volume, micromechanics model for cleavage fracture to correct measured $J_{c}$-values for the mechanistic effects of large-scale yielding. The model defines a constraint "corrected" $J_{0}$-value, denoted $J_{S S Y}$ in earlier work, for each measured $J_{c}$-value at fracture. The corrected $J_{0}$-value generates the same stressed-volume of material at the crack tip in small-scale yielding (SSY with $T=0$ ) that $J_{c}$ generates at the crack tip in the test specimen at fracture. Under increased loading in test specimens, the ratio of applied $J$ to $J_{0}\left(J / J_{0}\right)$ exceeds unity as large-scale yielding causes constraint to fall relative to SSY reference condition. For example, the $J / J_{0}$ ratio grows much larger than 4-5 in shallow notched bend specimens $(a / W<0.2)$.

When small amounts of ductile tearing precede failure by cleavage, this picture becomes more complex. Stress fields ahead of a growing crack differ from those of a stationary crack and growth exposes additional volumes of material to high stresses as the tip moves forward. Wallin [34] proposed simple extensions of his WST statistical model [33] to include the first order effects of stress field changes and additional volume. Recent work by Varias and Shih [31] on steady-state crack growth in SSY and by O'Dowd, et al. [21] for transient growth in SSY demonstrates clearly the development of high constraint conditions ahead of the growing crack, even when growth begins under low constraint conditions $\left(T / \sigma_{0}<0\right)$. These finite element analyses reveal a significant elevation of stress triaxiality caused by macroscopic sharpening of the extending tip and by additional elastic strains as the crack extends forward into previcusly unyielded material. In fracture test specimens, however, these effects may be partially or completely offset by the large amount of plastic deformation present at $J_{I c}$ and the additional plastic deformation associated with the increased applied $J$ required to grow the crack. The initial $a / W$ ratio, the tearing modulus, strain hardening exponent and specimen size interact in a complex manner to define the evolving near-tip conditions for cleavage fracturc. 
This work extends the stressed-volume constraint model for cleavage fracture to include the mechanistic effects of small amounts of ductile tearing on the near-tip stress fields. Plane-strain, finite element analyses are described for SE(B) specimens having both shallow and deep cracks $(a / W=0.1,0.5)$ for materials with hardening exponents $n=5,10$. The models are loaded to prescribed levels of $J=J_{I c}$ after which crack growth occurs consistent with the specified resistance curve, $J_{R}-\Delta a$. A parameter study for a range of $J_{I c}$ and tearing modulus values provides the stress fields ahead of the growing cracks needed to construct $J / J_{0}$ ratios of the constraint correction model. In this process, we assume that ductile crack growth prior to cleavage fracture introduces additional complexity only in the resolution of near-tip stresses, i.e., that the microstructural resistance to cleavage initiation remains stress-controlled and unaffected by the small amounts of prior stable tearing (usually 1-2 mm or less).

Given a measured toughness value at cleavage $\left(J_{c}\right)$ and estimated values for the tearing modulus and $J_{I c}$, the new model corrects for the combined effects large-scale yielding and ductile crack extension. Necessary graphs and procedures are provided in the last section to apply the model to experimental data sets. Statistical analyses, e.g., Weibull methods, developed for interpretation of cleavage fracture data should be applied to data sets of corrected $J_{0}$-values, with no distinction then needed between corrected values for specimens with/without prior tearing. The paper concludes with example applications of the proposed model to data sets for two pressure vessel steels (A515, A533B).

\section{Micromechanical Constraint Corrections}

Dodds and Anderson [3,7] show that by quantifying the effects of large-scale yielding (LSY) on the relationship between microscale crack driving force (e.g. neartip stresses and strains) and macroscale crack driving force (e.g. J, CTOD), the inplane size effect on cleavage fracture toughness can be predicted rigorously without resort to empirical arguments. Statistical analyses should be applied only to constraint "corrected" measures of fracture toughness [1,35]. Size effects become steadily more pronounced as load increases due to the deviation of crack-tip region deformations from the small-scale yielding (SSY) conditions under which single parameter fracture mechanics apply $[22,26]$. When $J$ (or equivalently CTOD) no longer describes the crack-tip fields, a micromechanics failure criterion is required to establish the near-tip conditions at fracture. Finite element analysis provides a means to quantify the geometry dependent relations between these micromechanical failure conditions and macroscale crack driving force. This permits (in principle) prediction of fracture in any body from toughness values measured using standard specimens. This section describes the micromechanism for cleavage fracture developed in previous work to correct measured fracture data for constraint loss due to large-scale yielding and then discusses the basis for extending the methodology to include small amounts of ductile tearing prior to cleavage fracture.

\subsection{Transgranular Cleavage Mechanism}

A number of micromechanical models for transgranular cleavage fracture have been proposed, most derive from weakest-link statistics (see review by Wallin [35]). The weakest-link models assume the largest or most favorably oriented fracturetriggering particle controls the cleavage failure. The actual trigger event involves a local Griffith instability of a microcrack which forms at a microstructural feature 
such as a carbide or inclusion; satisfaction of of the Griffith energy balance occurs when the critical stress is reached in the vicinity of the microcrack [24]. The size and location of the triggering microstructural feature(s) dictate the fracture toughness and contribute to the scatter observed in results of cleavage fracture tests.

The Griffith instability criterion implies fracture at a critical normal stress near the crack tip; the statistical sampling aspect of the mechanism (i.e., the probability of finding a triggering microfeature near the crack tip) suggests a dominant role for the volume of material within a process-zone over which the opening mode stress exceeds a threshold value sufficient to initiate cleavage. The probability of cleavage fracture in a cracked specimen may then be expressed in the following general form:

$$
F=F\left|V\left(\sigma_{c}\right)\right|
$$

where $F$ is the failure probability and $V\left(\sigma_{c}\right)$ is the volume of material ahead of the crack tip over which the principal stress $\left(\sigma_{1}\right)$ exceeds a specified value $\sigma_{c}$. This form of $F$ applies to any fracture process controlled by maximum principal stress, not just weakest-link failure $[2,35]$. In particular, the $F$ criterion of $\mathrm{Eq} 1$ does not require material-specific assumptions for the distribution and strength of cleavage triggering particles.

The present methodology does not attempt to predict absolute values of $J_{c}$. from metallurgical parameters that describe the distribution and strength of cleavage triggering particles. Rather, the micromechanical model predicts the variation of fracture toughness with constraint changes for a given material/temperature by scaling to a reference constraint condition. The crack-tip stress fields in a test specimen are compared to those for SSY with $T=0$. A $J$-like parameter, denoted $J_{0}$, is obtained from this comparison to the reference solution. $J_{0}$ is the $J$ to which the SSY model (infinite body) must be loaded to achieve the same stressed volume, and thereby the same likelihood, $F$, of cleavage fracture, as in a finite body. With this model, the assurance of equally stressed volumes of material at fracture does not imply equivalence of the individual stress components beyond SSY conditions, however, such a requirement does not appear strictly essential.

\subsection{Constraint Corrections}

Consider the family of near-tip stress fields applicable to finite bodies described in terms of the $J-Q$ theory 119,20$]$

$$
\frac{\sigma_{i j}}{\sigma_{0}}=f_{i j}\left(\frac{r}{\cdot J / \sigma_{0}}, \theta ; Q\right)
$$

where $Q \sigma_{0}$ denotes an approximately constant, hydrostatic stress in the forward sector, $|\theta|<90^{\circ}$, that defines the local deviation of the finite body stresses from those of the small-scale yielding reference field (the $Q=0$ solution is taken to be that for SSY, $T=0$ ). By employing the above family of near-tip stress fields, the maximum principal stress also has the form

$$
\frac{\sigma_{1}}{\sigma_{0}}=f_{1}\left(\frac{r}{J_{0} / \sigma_{0}}, \theta ; Q\right)
$$

For any given value of $Q$ and $\theta, \sigma_{1} / \sigma_{0}$ decreases monotonically once $r$ extends beyond the finitely deformed region of $r \geq J / \sigma_{0}$. Rearrangement of the above expression furnishes a relation for the distance $r$ as a function of $\theta$ and $\sigma_{1} / \sigma_{0}$ as

$$
r=\frac{J}{\sigma_{0}} g_{1}\left(\theta ; \sigma_{1} / \sigma_{0}, Q\right)
$$


where $g_{1}$ is restricted to values $\gtrsim 1$ to avoid locations with the finitely deformed region. Consider a particular level of the principal stress $\sigma_{1} / \sigma_{0}$. The area $A$ over which the principal stress exceeds $\sigma_{1} / \sigma_{0}$ is given by

$$
A=\frac{J^{2}}{\sigma_{0}^{2}} h\left(\sigma_{1} / \sigma_{0} ; Q\right), \quad h=\frac{1}{2} \int_{-\pi}^{\pi} g_{1}^{2}\left(\theta ; \sigma_{1} / \sigma_{0}, Q\right) d \theta .
$$

The area enclosed by the contour of level $\sigma_{1} / \sigma_{0}$ depends on $J$ as well as the triaxiality of the near-tip fields identified with $Q$. To fix ideas, let $A_{0}$ and $J_{0}$ designate the area and $J$ associated with the $Q=0$ field, and let $A_{F B}$ and $J_{F B}$ designate the area and $J$ associated with $\&$ crack in a finite body with $Q \neq 0$. Then we have

$$
A_{0}=\frac{J_{0}^{2}}{\sigma_{0}^{2}} h_{0}\left(\sigma_{1} / \sigma_{0}\right) ; \quad h_{0}=\frac{1}{2} \int_{-\pi}^{\pi} g_{1}^{2}\left(\theta ; \sigma_{1} / \sigma_{0}, Q=0\right) d \theta
$$

and

$$
A_{F B}=\frac{J_{F B}^{2}}{\sigma_{0}^{2}} h_{F B}\left(\sigma_{1} / \sigma_{0}\right) ; \quad h_{F B}=\frac{1}{2} \int_{-\pi}^{\pi} g_{1}^{2}\left(\theta ; \sigma_{1} / \sigma_{0}, Q\right) d \theta
$$

Upon initial loading of the finite body, $Q=0$ so that $h_{F B}=h_{0}$. As the load increases, plasticity spreads over the body, $Q$ becomes non-zero, and $h_{\mathrm{FB}}$ begins to deviate from $h_{0}$.

For a given material and temperature, fracture occurs upon the attainment of equivalent stressed volumes $\left(A_{F B} \times\right.$ thickness $\left.B\right)$ for cleavage fracture in different specimens. The ratio of applied $J$-values in a finite body and the reference $Q=0$ stress state that generate equivalent stressed volumes is found by equating areas in Eqs 6 and 7 to yield

$$
\frac{J_{F B}}{J_{0}}=\sqrt{\frac{h_{0}\left(\sigma_{1} / \sigma_{0}\right)}{h_{F B}\left(\sigma_{1} / \sigma_{0}\right)}}=\sqrt{\frac{A_{0}}{A_{F B}}} .
$$

The $J$ ratios are evaluated using Eq 8 at each loading level and for a range of principal stress values. The ratio quantifies the size and geometry dependence of cleavage fracture toughness. Consider, for example, a test specimen that fails at $J_{c}=200 \mathrm{~kJ} / \mathrm{m}^{2}$. Suppose the computed ratio $J_{F B} / J_{0}=2$ at fracture $\left(J_{F B}=J_{c}\right)$ in the test specimen; then a much larger specimen made from the same material and tested at the same temperature is predicted to fail at $J_{c}=100 \mathrm{~J} / \mathrm{m}^{2}$ (the larger specimen fails under SSY conditions). Similarly, the fracture toughness ratios for test specimens with the same absolute size but varying crack depths-to-specimen widths, $a / W$, may be quantified. The model predicts a sharp increase in fracture toughness with decreasing $a / W$ ratio.

An often overlooked benefit of both the $J-Q$ description of near-tip fields and this constraint model for cleavage fracture involves the capability to model arbitrary material hardening. A finite element analysis of the SSY reference condition may be executed using a description of the uniaxial material response other than RambergOsgood or the linear, power-law models (finite strains and $J_{2}$ flow theory plasticity may be modeled as well). Fracture test specimens (and structural components) are then modeled using the same procedures with $\boldsymbol{Q}$ and the constraint model for cleavage constructed as above. These approaches rely on the concept of similarity under SSY conditions; a concept much broader than is inferred by asymptotic analyses 
which invoke incompressibility, power-law hardening and small-strain theory to develop expressions for crack-tip fields.

The key question to resolve with the constraint model concerns the sensitivity of the $A_{F B} / A_{0}$ and $J_{F B} / J_{0}$ ratios on $\sigma_{1} / \sigma_{0}$. Numerical computations $[3,13,14]$ reveal a weak dependence on $\sigma_{1} / \sigma_{0}$ in common fracture specimens until the overall bending deformation impinges significantly on the crack-tip field. This occurs more readily for low amounts of strain hardening and for deeply notched specimens and much less so for tension dominated geometries and for materials with greater amounts of strain hardening. The weak dependence of $J_{F B} / J_{0}$ ratios on $\sigma_{1} / \sigma_{0}$ derives from the observation that stress fields among fracture specimens vary primarily due to the hydrostatic contribution (as described by the $J-Q$ theory). The differences in hydrostatic stress relative to the SSY $(Q=0)$ field alter predominantly the absolute size of principal stress contours but not the angular form defining their shapes [8].

\subsection{Application of the Constraint Corrections in Fracture Testing}

Figure 1 provides typical results obtained through finite element modeling (plane strain). The specimens are $\mathrm{SE}(\mathrm{B}) \mathrm{s}$ with $a / W=0.1,0.5$ modeled with a Ramberg-Osgood material having strain hardening exponents $n=5,10$. Values of $J_{F B}$ and $J_{0}$ are plotted on separate axes to facilitate the constraint correction of experimental data. Points on the curves describe $\left(J_{F B}, J_{0}\right)$ pairs that produce equal stressed volumes of material in the test specimen and in SSY. Path A-B-C indicated in Fig. 1 (b) illustrates the procedure to correct for the effects of large-scale yielding in measured cleavage fracture toughness data $\left(J_{c}\right.$ value at $\left.\mathbf{A}\right)$ by determining the geometry independent fracture toughness $\left(J_{0}\right.$ value at $\left.\mathbf{C}\right)$. To simplify application of the constraint correction procedures, curve fits to finite element results of the form shown in Fig. 1

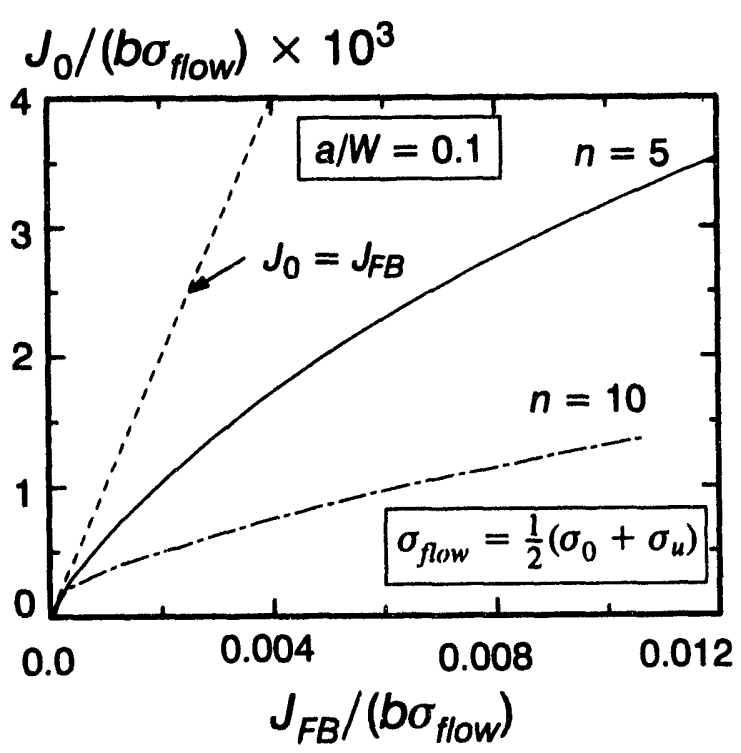

(a)

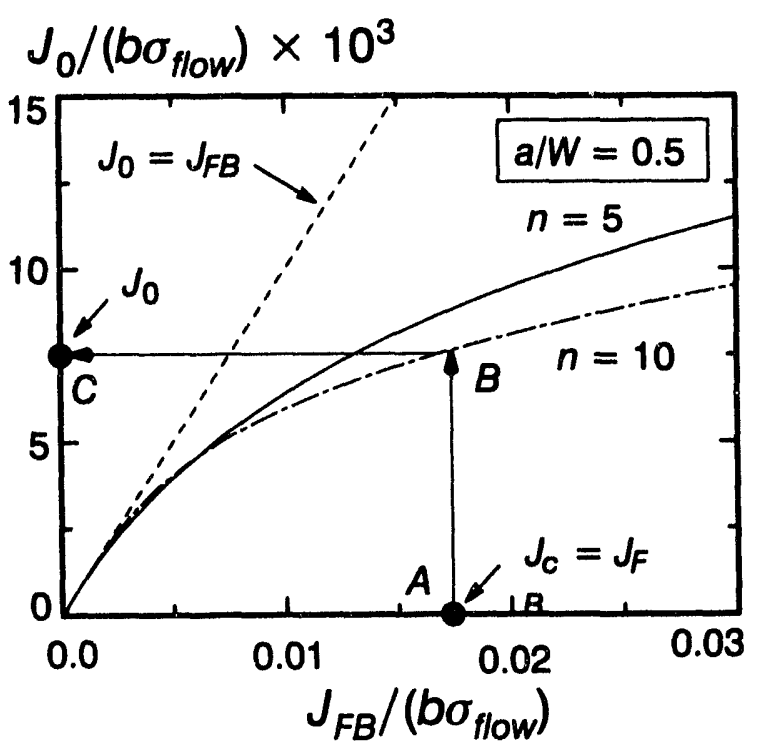

(b)

FIG. 1-Cleavage constraint models for stationary cracks in $S E(B)$ specimens with $a / W=0.1,0.5 ; n=5,10 ; E / \sigma_{0}=500 ;$ using contour areas for $\sigma_{1} / \sigma_{0}=2.7$. 
are available for a wide range of hardening exponents and $a / W$ ratios [8]. Moreover, crack opening stresses on the remaining ligament may be used to compute the $J_{F B} / J_{0}$ ratios rather than the more complex contour area procedure [8]. Applications of this technique to structural steels, including A36, A515 and A533B [12,29,35], have been successful in removing the geometry dependence of $J_{c}$ values.

Three-dimensional analyses in-progress for the same SE(B) specimens (with $B \times B$ cross sections) reveal significant differences with the plane-strain correction model for the deep-notch specimen but essentially no differences with plane-strain results for the shallow-notch specimen. The 3-D analyses show that SSY conditions for the $a / W=0.5$ specimen are maintained to greater deformation levels $\left(a \sigma_{0} / J=50\right.$ vs. 150 for plane-strain) on the mid-thickness plane; at positions on the crack front mid-way between the center-plane and outside surface, the constraint levels fall below those predicted by the plane-strain model. For the shallow-notch specimen, constraint conditions on the mid-thickness plane closely match those predicted by the plane-strain model. Introduction of the finite thickness, $B$, requires modification of the constraint correction model to accommodate the interaction of thickness with $a / W$ ratio, $W / B$ ratio and material strain hardening. The concept of an effective thickness, $B_{\text {eff }}$, is being explored to describe constraint across the crack front relative to the mid-thickness constraint in a meaningful way for cleavage fracture. The relative effects of crack growth in a plane-strain vs. a fully 3-D model (with curved crack fronts during growth allowed) appear to be a very important, yet currently unresolved issue (the computational resources and modeling complexity for growth analyses in 3-D are much greater).

\subsection{Extension to Include Effects of Ductile Tearing}

Small amounts of ductile crack extension, typically less than 1-2 mm, preceding cleavage fracture may alter the structure and severity of the near-tip stress fields. The extending tip develops a sharp opening profile, relative to the blunt profile at initiation of tearing, which elevates the stress and decreases the distance from the crack tip to the peak stress location. When SSY conditions prevail, stresses at distances greater than $J / \sigma_{0}$ from the tip increase as well due to additional elastic strains as the plastic zone pushes forward into unyielded material. Crack growth also subjects a larger volume of material, $\Delta V \times\left(J / \sigma_{0}\right) \times \Delta a \times B$, to high stress levels near the tip and thus raises the probability of sampling a critical, fracture-triggering particle.

At the metallurgical length-scale characteristic of carbides and inclusions, tearing and large plastic deformation may affect the fundamental cohesive strength across cleavage planes. More likely at this length-scale, tearing makes the crack front considerably more torturous than the blunted tip of the stationary crack, thus increasing the cleavage energy needed to initiate a macroscopic fracture. In addition, material damage caused by the formation and growth of voids within the zone of finite strains may alter somewhat the macroscopic stress field [15]. These are unresolved issues.

To extend the constraint correction model given present knowledge, these metallurgical aspects of tearing are considered to have secondary importance relative to the increased near-tip stresses and the additional volume of material subjected to higher stresses as a consequence of the crack extension. The effects of ductile tearing thus appear as changes in the stressed volumes of material, $A_{F B} \times B$, where crack 
growth changes the area enclosed within principal stress contours relative to a stationary crack loaded at the same $J_{F B}$.

Figure 2 illustrates schematically the impact of tearing on the constraint correction model. The specimen follows the model for a stationary crack until the onset of ductile tearing at $J_{F B}=J_{I c}$. Under continued loading, the new model including growth predicts an increase of $J_{0}$-values relative to continued loading of the stationary crack, i.e., tearing increases the constraint. The increase of $J_{0}$-values due to tearing depends on the amount of plastic deformation in the specimen at $J_{I c}$ and on the $R$-curve followed prior to cleavage fracture. To simplify initial development of the model, a constant tearing modulus, $T_{J}=\left(E / \sigma_{0}^{2}\right) d J / d a$, is adopted to describe the $R$ curve for typical extensions of 1-2 mm. Consequently, the evolution of cracktip constraint in simple fracture specimens with ductile growth may be expressed by a function of the form

$$
\frac{J_{F B}}{J_{0}}=\mathbb{C}\left(\frac{\sigma_{1}}{\sigma_{0}}, n, \frac{E}{\sigma_{0}}, \frac{a_{0}}{W}, \frac{W \sigma_{0}}{J_{l c}}, \frac{\Delta a}{W}, T_{J}\right)
$$

where $\mathbb{C}$ denotes the "constraint" function for cleavage fracture with prior ductile tearing. The non-dimensional groups $W \sigma_{0} / J_{I c}, a_{0} / W, \Delta a / W$ and $T_{J}$ describe the dependence on crack growth and absolute size, while $E / \sigma_{0}$ and $n$ define the material yield and hardening properties. Although included Eq 9, a weak dependence of $\mathbb{C}$ on $\sigma_{1} / \sigma_{0}$ is expected.

$J_{0}$-values derived from both instantaneous and cumulative contour areas are provided for initial development of the growth correction model (see Fig. 3). The instantaneous areas enclosed within principal stress contours are computed from a snapshot of the stress field ahead of the growing crack - points on such contours all lie within the forward sector, $|\theta|<90^{\circ}$ (see area $A$ in Fig. 3). Figure 3 also illustrates the construction of cumulative contour areas using the envelope of maximum

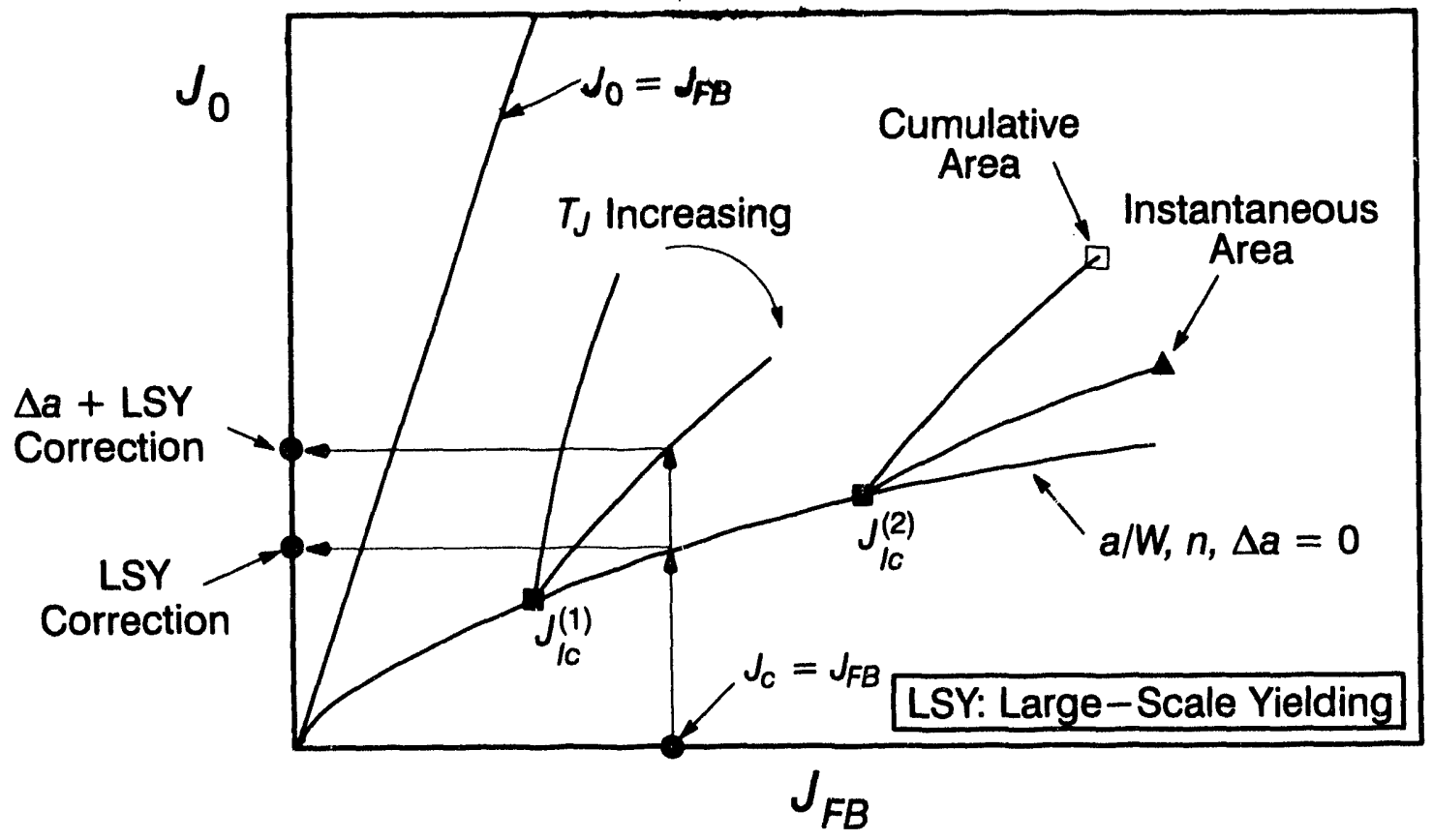

FIG. 2-Schematic illustration of growth effects on constraint correction model. 
principal stresses experienced by material along the crack plane during growth. The cumulative areas, defined as areas enclosed within the contour envelope, may be substantially larger than instantaneous areas which leads to the larger $J_{0}$-values indicated in Fig. 2 for the cumulative area correction.

The proposed constraint model including crack growth maintains the relative simphicity of the original version which corrects only for (in-plane) effects of largescale yielding. Furthermore, development of the new model to account only for tearing effects on the microscale driving force (the local crack tip stresses and stressed volume), implies that corrected toughness values, with and without ductile tearing prior to cleavage, should receive equal weight in statistical analyses, e.g., Weibull models $[34,35]$.

\section{Numerical Models for Growth Analyses}

Finite element models of the type shown in Fig. 4 are employed to perform plane strain, nonlinear analyses of $S E(B)$ specimens including small amounts of ductile crack growth. Both shallow crack $(a / W=0.1)$ and deep crack $(a / W=0.5)$ specimens are c'nalyzed. Symmetry about the crack plsane permits modeling of only one-half of each $\mathrm{SE}(\mathrm{B})$ specimen. The finite elements are conventional eight-noded isoparametrics with reduced $(2 \times 2)$ Gauss integration. Square elements in the crack-tip region and along the crack plane are defined to simplify the growth analyses and to permit uniform increments of crack extension. Crack opening profiles and stresses ahead of the growing crack seem to be resolved adequately when the crack-tip element size, $L_{e}$, is smaller than $\approx 0.5 \times$ the CTOD at initiation $\left(\delta_{I c}\right)$. Stationary crack solutions for comparison are also generated with these models.

The finite element models are loaded by displacement increments imposed on a single centerplane node as shown in Fig. 4. An improved form of the traditional node release technique is employed to implement crack extension. The imposed loadpoint displacement is adjusted iteratively, concurrent with a one-element crack ex-

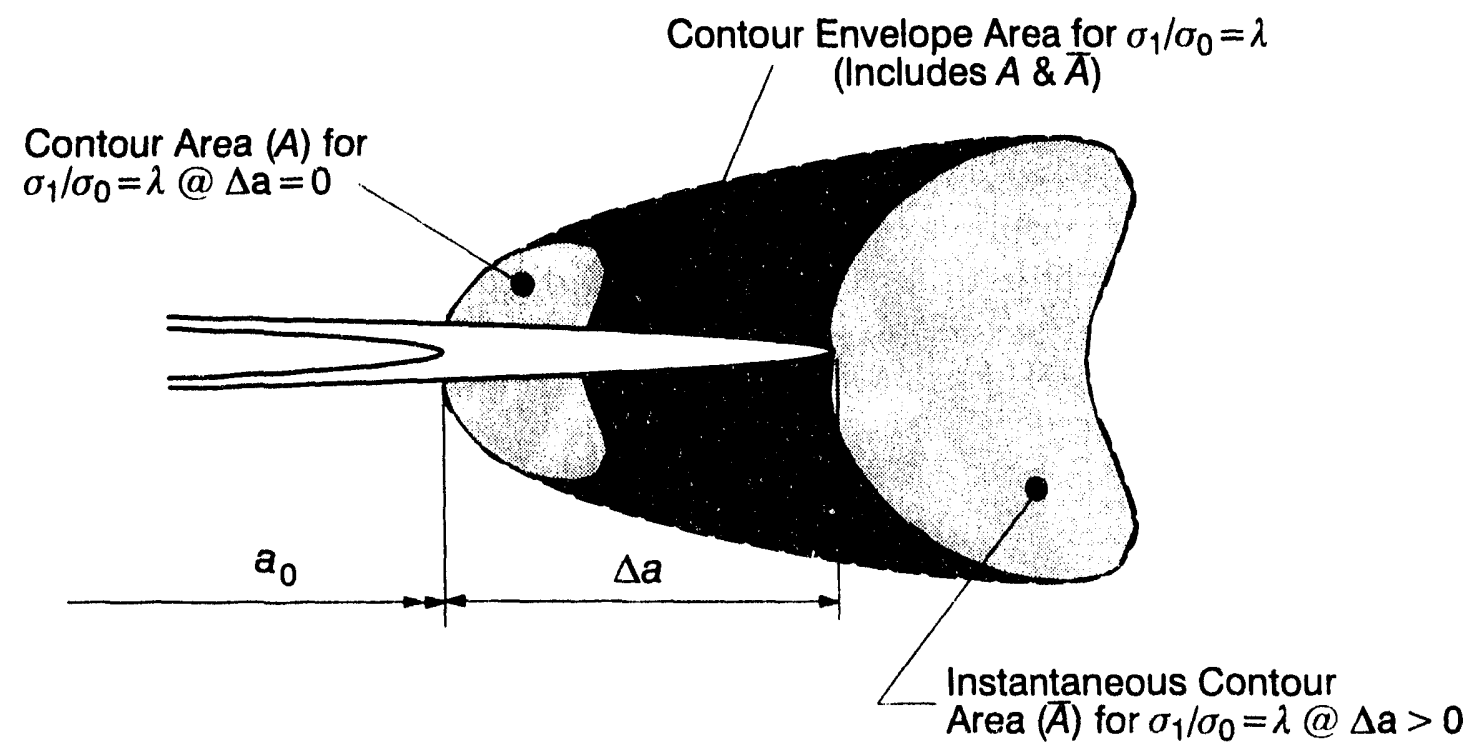

FIG. 3-Schematic illustrating construction of principal stress envelope for growing cracks. 


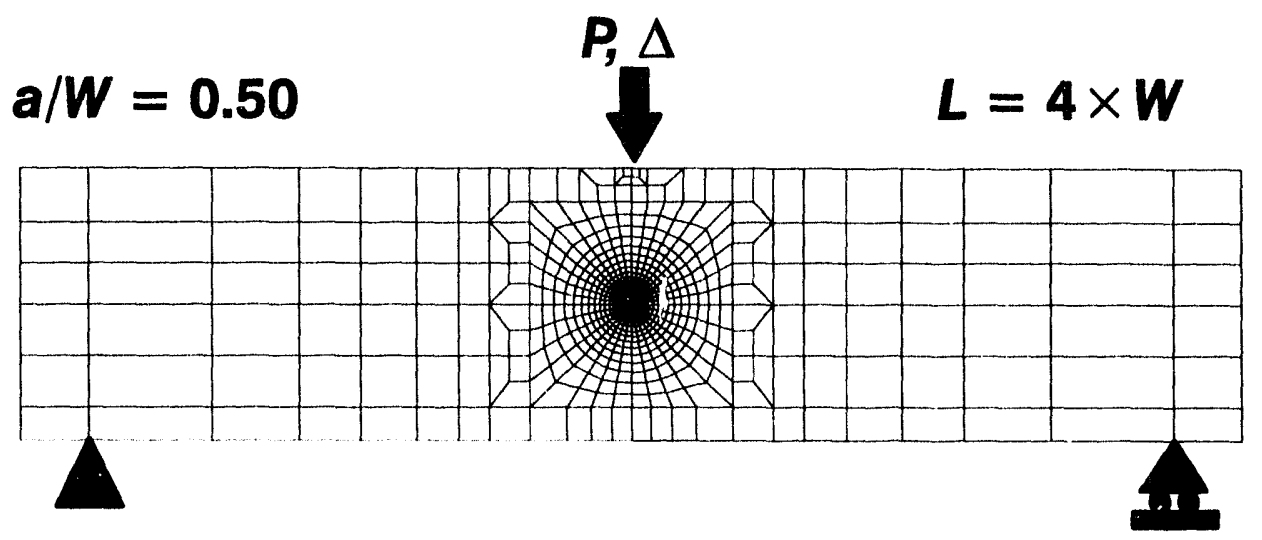

(a)

Finite element mesh $\mathrm{SE}(\mathrm{B})$ specimen with deep crack $(a / W=0.5)$. Elements are 8 -node isoparametrics.

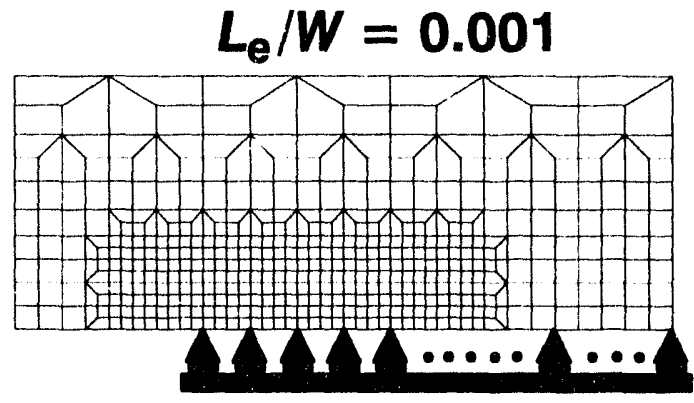

Crack-plane elements are square to simplify crack

(b) growth analyses. $L_{e}$ denotes side length of the square crack plane elements.

FIG. 4-Finite element models for $S E(B)$ specimens.

tension, such that the crack growth criterion is always satisfied at completion of the node release. This procedure retains the computational convenience of the node release technique while eliminating convergence problems due to artificial unloadings encountered with the traditional implementation (see [9] for additional details).

The uniaxial stress-strain relationship follows the Ramberg-Osgood model, $\varepsilon / \varepsilon_{0}=\sigma / \sigma_{0}+\alpha\left(\sigma / \sigma_{0}\right)^{n}$. Two typical values of the material hardening coefficient $(n=5$ and 10) are selected in the analyses of $\mathrm{SE}(\mathrm{B})$ specimens to represent high $(n=5)$ and medium $(n=10)$ hardening materials. All computations use $E / \sigma_{0}=500$, Poisson's ratio $v=0.3$ and $\alpha=1$.

The computations reported here are carried out using a large-rotation, finite strain constitutive model based on the incremental, flow theory of plasticity $[9,10]$. A companion study using a conventional, small-strain (incremental) plasticity formulation predicts essentially identical results for crack opening profiles and stresses ahead of the growing tip. Recent work by Liu and Drugan reach similar conclusions [23]. 


\subsection{Crack Growth Parameters}

The specified value of $J_{I c}$, relative to specimen geometry, size and material flow properties, sets the severity of plastic deformation in an $\mathrm{SE}(\mathrm{B})$ specimen at the initiation of ductile growth. Values of $W \sigma_{0} / J_{I c}=480 \rightarrow 80$ are defined to achieve conditions at initiation of growth ranging from essentially SSY to fully formed plastic hinges.

Once $J$ reaches the specified initiation toughness, $J_{I c}$, subsequent crack. extension follows an $R$-curve defined by a constant tearing modulus, $T_{J}$. Selected values for the tearing modulus of 15,40 and 83 represent relatively low values characteristic of higher-strength steels with moderate-to-low strain hardening. Values on the order of 200-400 occur during the early stages of crack growth in some lowerstrength steels with moderate-to-high strain hardening. These large values appruach one-half the slope of the blunting line, $d J / d a=2 \sigma_{0}$ (defines a tearing modulus of $\left.T_{J B L}=2 E / \sigma_{0}\right)$. The lower values of $T_{J}$ specified for the $\mathrm{SE}(\mathrm{B})$ analyses accentuate the effects of crack growth - much larger values of tearing modulus drive the response toward the stationary crack solution, i.e., the loss of constraint due to large increases in $J$ and plastic deformation overwhelm the increased constraint from small crack extensions. Analyses for materials with high tearing modulus (200-500) are also performed to support application of the growth constraint model to currently available experimental results.

\subsection{J-Values During Crack Growth}

$J$-values during crack growth analyses in the $\mathrm{SE}(\mathrm{B})$ specimens are computed with the domain-integral procedure [18]. Figure 5 shows the typical variation of $J-$ values with increasing generalized radius of the integration domain for both a stationary crack and a growing crack. A domain "ring" denotes a sequence of connected elements, enclosing the tip at a remote distance, which make non-zero contributions to $J$. Starting with the ring of elements at the current crack tip, $J$ is computed independently over each successive ring of elements. Figure 5 (a) shows a weak path dependence of $J$ on the domain size (i.e., distance of ring from tip) for the stationary crack loaded to $J=J_{I c}$. The small degree of path dependence just outside the cracktip elements arises from nonproportional straining in the incremental plasticity theory. Once the domains extend beyond $10 \%$ of the remaining ligament, $j$ becomes path-independent; this value is referred to here as the far-field $J$ and is denoted $J_{\text {far. }}$.

In contrast to the stationary crack, $J$-values for the growing crack exhibit a much stronger path-dependence as shown in Fig. 5 (b). Near zero $J$-values are computed over domains very close to the crack-tip. Figure 5 (b) shows that the $J$-value at $\Delta a=10 \times \delta_{I c}$ reaches a nearly path-independent value once domains extend beyond $20-25 \%$ of the remaining ligament. The necessity for $J$ evaluation at large distances from the growing crack limits the maximum amount of crack growth permitted in the SE(B) analyses. As the largest domain is redefined for each increment of growth, the domain may extend into the more coarse mesh remote from the tip or reach the specimen edges ahead of or behind the crack tip.

In the experimental determination of a $J_{R}-\Delta a$ response, $J$-values are estimated as a fraction of elastic and plastic work done on the specimen. By treating the finite element $P-\Delta_{L L D}$ results (including crack growth) as experimental records, a comparison of the domain integral and experimental $J$ definitions becomes possible. For deep notch SE(B) specimens, ASTM E1152-87 [4] outlines the procedure to estimate 


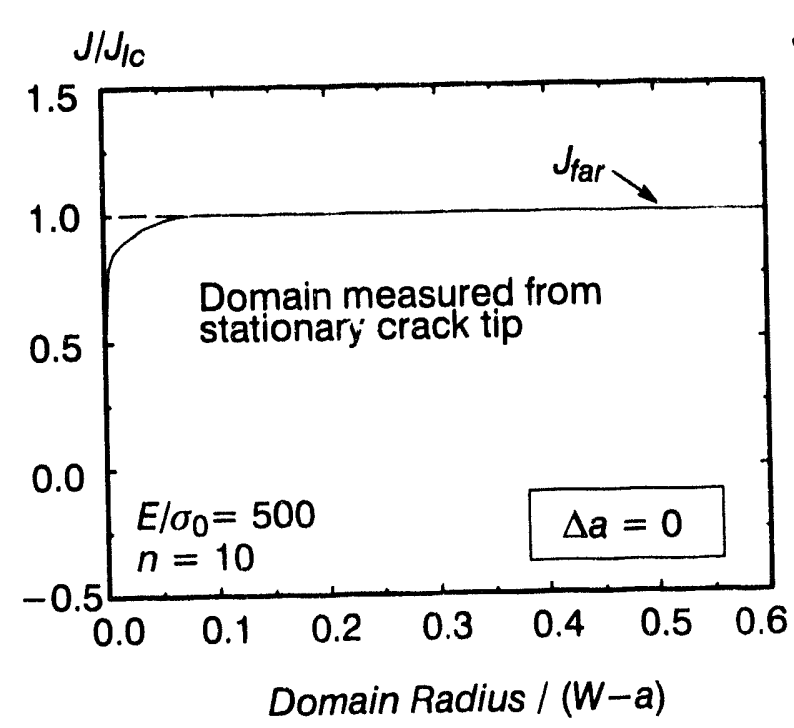

(a) Stationary Crack

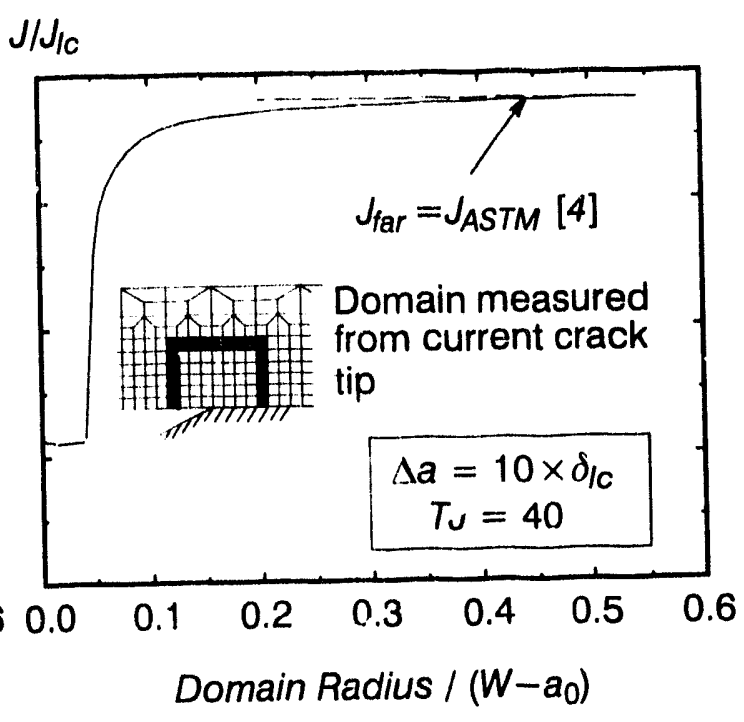

(b) Growing Crack

FIG. 5-J-integral variation over domain rings for both stationary and growing cracks for $S E(B)$ with a/W=0.5.

$J$-values $\left(J_{A S T M}\right)$ from experimentally measured load, load-line displacement and crack length records. (The ASTM procedure assumes nnnlinear elastic material response as well and thus the $J_{A S T M}$ values are often referred to as "deformation" $J-$ values, $\left.J_{D}\right)$. For both hardening exponents $(n=5$ and 10$)$, the finite element $J_{f a r}$ and $J_{A S T M}$ values are indistinguishable over the full crack growth history. Such close agreement of finite element and experimental estimates for $J$-values with crack growth is essential for subsequent application of the growth constraint model.

\section{Growth Effects on Crack-Tip Fields}

\subsection{Crack Opening Profiles}

Figure 6 compares crack opening profiles for stationary crack and growing cracks in SE(B) specimens. The effects of different tearing modulus are shown for crack growth initiated at the same normalized value of $J_{I c}$. Profiles for growing cracks exhibit a macroscopically "sharp" tip for all values of tearing modulus, in contrast to the severely blunted tip of the stationary crack. While the different values of tearing modulus strongly affect the immediate crack opening angle (CTOA), as indicated on the figure, there is negligible effect upon further opening behind the initial (blunted) tip when displacements are normalized by $J / \sigma_{0}$. Following a short transient period when the crack grows through the first element at the stationary tip, the crack-tip opening angles remain constant and increase with the specified $T_{J}$. The constancy of CTOA with $T_{J}$ observed previously in SSY analyses of crack growth $[25,28]$ carries forward to the $\mathrm{SE}(\mathrm{B})$ specimens.

\subsection{Crack Opening Stresses on Remaining Ligament}

Figure 7 illustrates the typical effects of growth on the crack opening stress which acts on the remaining ligament. The analyses consider two geometries 
$(a / W=0.1,0.5)$ and two hardening exponents $(n=5,10)$, with results for each combination of these parameters shown for one value of the tearing modulus $\left(T_{J}=83\right)$. Crack growth begins in the analyses at the common value $J_{I c}=W \sigma_{0} / 240$. The results for each case contain two curves: one for the growing crack of length $a_{0}+\Delta a$ and one for the stationary crack of length $a_{0}$, with both configurations loaded to the same $J$. The amount of crack extension relative to the CTOD at initiation varies with the strain hardening even though the final $J$-values are $1.8 J_{I c}$ in each case. For reference, each figure also includes the corresponding steady-growth solution in SSY given by Varias and Shih [31] .

Sharpening of the crack tip during growth shifts the location of the peak stress n arer to the tip, with the largest (relative) shift for the lower amount of strain hardening. The peak stress location for both high and moderate hardening converges to $r \approx 0.25 J / \sigma_{0}$. As expected, the shallow crack specimens reveal significant loss of constraint relative to the deep crack specimens, with stresses for $n=10$ showing the most differences [compare stresses at the same $r /\left(J / \sigma_{0}\right)$ ]. At distances from the tip greater than about $J / \sigma_{0}$, crack growth in the $\mathrm{SE}(\mathrm{B})$ specimens does not alter significantly stresses on the remaining ligament. This behavior contrasts sharply with stresses for the steadily-growing crack in SSY; stresses larger than those for the non-growing crack are predicted over much greater distances from the tip [31]. In these SE(B) specimens, crack growth initiates and grows under conditions of largescale yielding on the ligament which appears to suppress other mechanisms of stress elevation beyond the sharpening effect.

For the $n=10$ material, the amplitude of peak stress during crack growth exceeds the amplitude of the corresponding stationary crack stress and, for the deep notch speciman, $: \cdots$ peak stress reaches the steady growth value in SSY. For the high hardenirg material $(n=5)$, the growth stresses appear to fall below the peak values withou: growth. The relative coarseness of the element mesh is clearly evident in the stress fields without growth for the $n=5$ material; the crack-tip opening

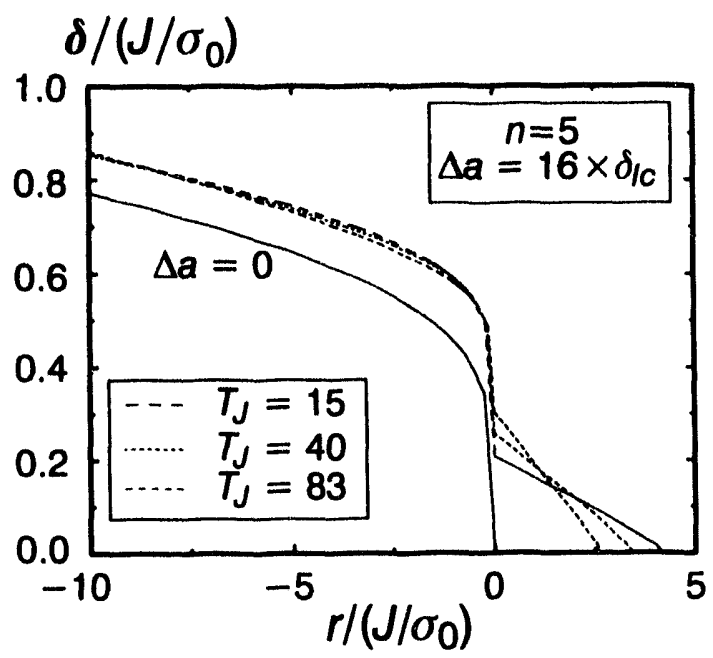

(a) $a / W=0.1$

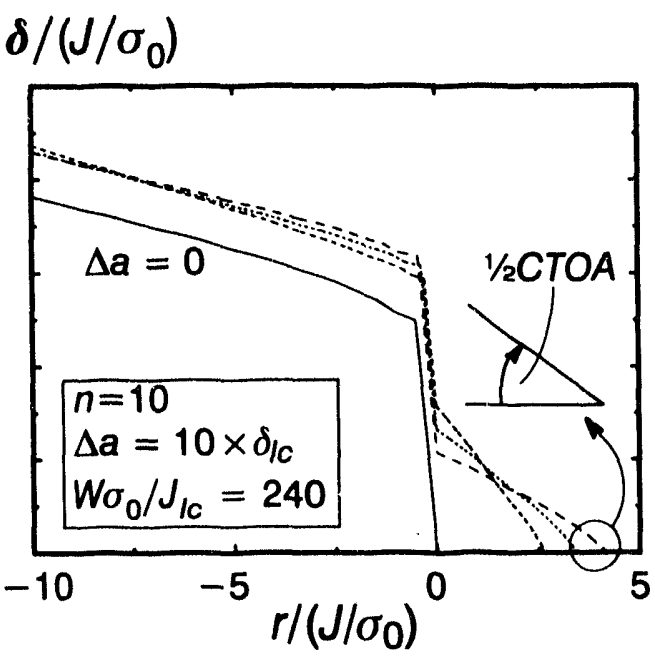

(b) $a / W=0.5$

FIG. 6-Opening profiles for stationary and growing cracks for shallow and deep notch $S E(B)$ specimens. 
displacement for this case is comparable to the tip element size. We expect that reanalysis using a finer mesh at the tip for $n=5$ would predict somewhat lower peak stresses for the stationary crack. Comparisons of crack opening stresses computed for other cases reveal that variations of $J_{I c}$ and the strain hardening exponent affect the stresses more significantly than variations of the tearing modulus when distances are scaled by $J / \sigma_{0}$ as in Fig. 7.

\subsection{Principal Stress Contours}

Crack opening stresses on the remaining ligament may not reflect changes in stresses away from the crack plane due to growth. Figure $8(a-b)$ show the effects of crack growth on the instantaneous principal stress contours for shallow and deep crack SE(B) specimens. Crack growth begins at the common value $J_{I c}=W \sigma_{0} / \mathbf{2 4 0}$ with results given in the figure for $T_{J}=83$ and $n=10$. Comparisons for contours other than $\sigma_{1} / \sigma_{0}=2.7$ shown in the figure reveal similar trends. In each case the stationary crack and growing crack contours correspond to the same applied $J$.

By using the current value of $J / \sigma_{0}$ to normalize distances from the crack tip on plots of principal stress contours, deviations in the stress triaxiality due to crack growth and increased loading (larger $J$ value) become very clear. Under SSY conditions the contours for a specified $\sigma_{1} / \sigma_{0}$ ratio coincide at all $J$-values when expressed on these normalized axes. When contours in a specimen at different loads ccincide, the near-tip constraint remains unchanged (the absolute size of the contour increases with $J$ but at the same rate for the two loading levels). When constraint increases (decreases) under increased loading or crack growth, the normalized contours must also increase (decrease) in size.

The normalized contours for the growing crack are distinctly larger than the contours for the stationary crack, especially for the shallow crack SE(B) specimen. For the $a / W=0.5$ specimen, the opening mode stresses on the remaining ligament do not indicate correctly the effects of crack growth on stresses elsewhere in the forward sector. The contours shown in the figure are those at the maximum crack growth considered of $\approx 10 \times \delta_{I c}$; contours examined at less crack growth show somewhat larger differences.

Figure $8(\mathrm{c}-\mathrm{d})$ summarize the areas enclosed by the instantaneous contours for a range of $\sigma_{1} / \sigma_{0}$ ratios. Areas are normalized by the similarity factor $\sigma_{0}^{2} / J^{2}$ (in SSY with $\Delta a=0$, the quantity $A\left(\sigma_{1} / \sigma_{0}\right) \sigma_{0}^{2} / J^{2}$ remains constant under increased loading). Three sets of results for comparison are shown on each figure: (1) areas for SSY without crack growth, (2) areas for the SE(B) specin ten at the maximum amount of crack extension considered, and (3) areas for the $\mathrm{SE}(\mathrm{B})$ specimen without crack growth but loaded to the same $J$-value as the growing crack. Figure 8 (c) for the shallow crack demonstrates the dramatic loss of constraint caused by the extensive plastic deformation; the areas differ by a factor of $\approx 100$ from SSY for $\sigma_{1} / \sigma_{1}=2.7$. Crack growth clearly increases the constraint, elevating the areas by factors of 2-3 above stationary crack levels. The deep crack specimens maintain much higher constraint as evidenced by the smaller differences in contour areas compared to SSY. Crack growth elevates near-tip stress triaxiality and increases areas enclosed within the principal stress contours. However, the effects of growth on the contours are much less pronounced than for the shallow crack.

Not surprisingly, the differences in contour areas between the stationary and growing crack increases with the $\sigma_{1} / \sigma_{0}$ ratio, that is, contours near the growing tip 


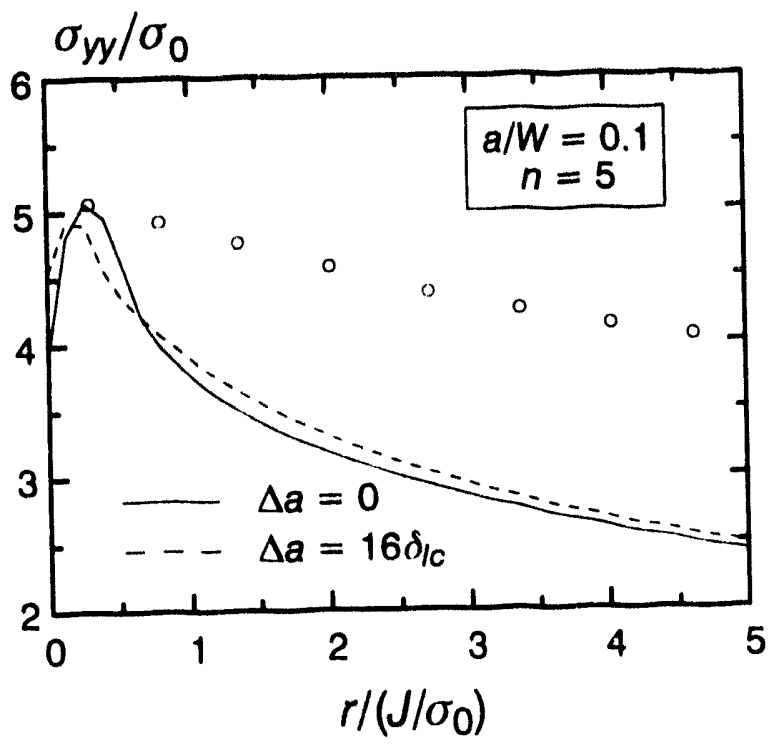

(a)

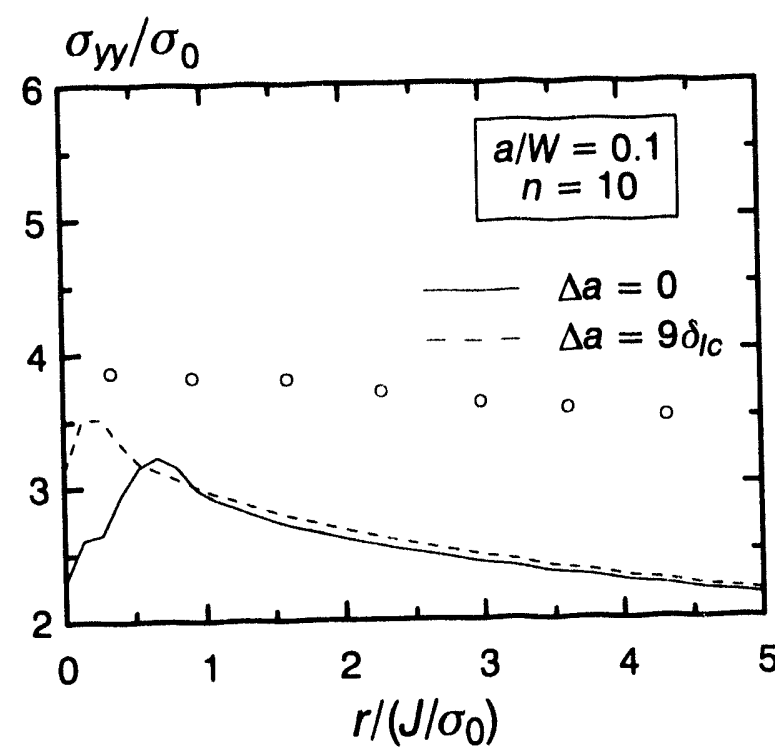

(c)

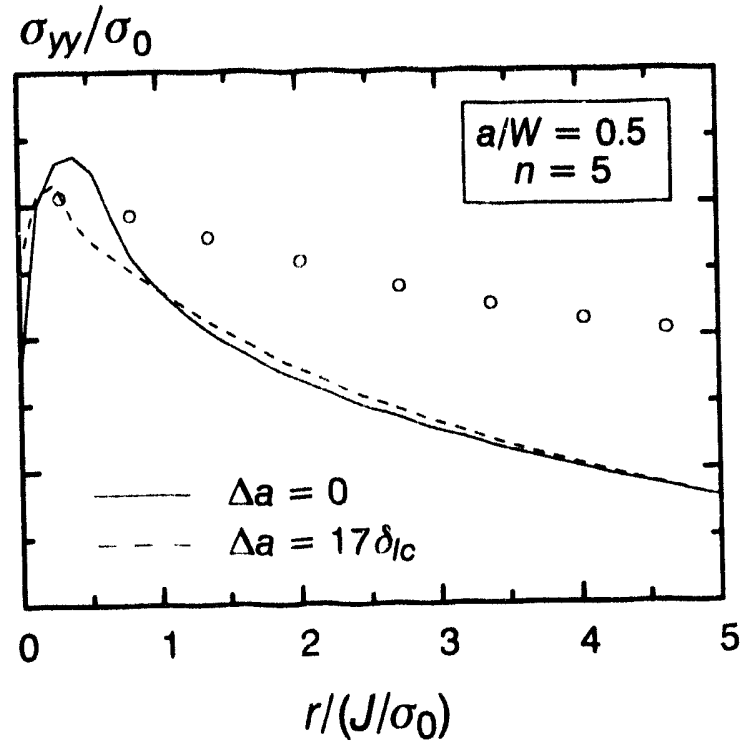

(b)

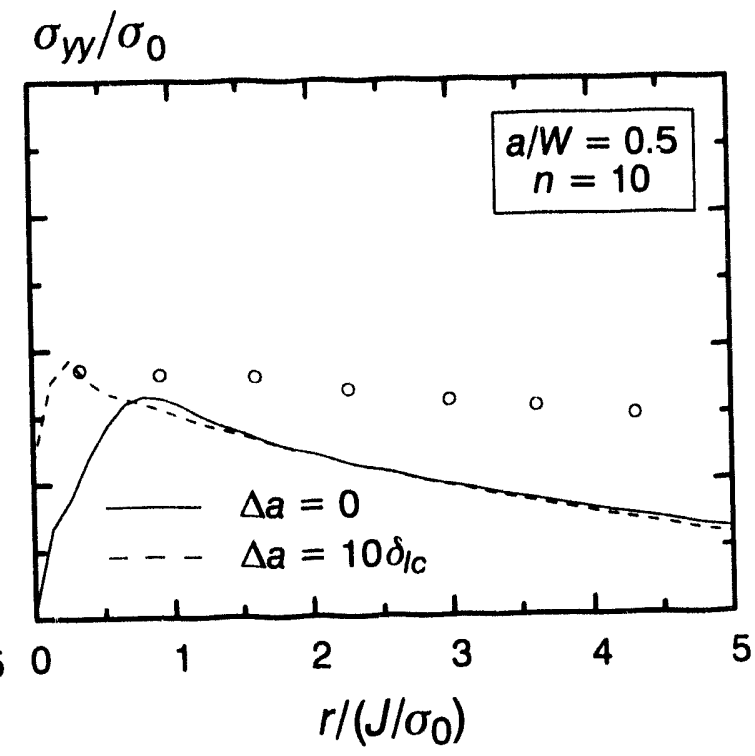

(d)

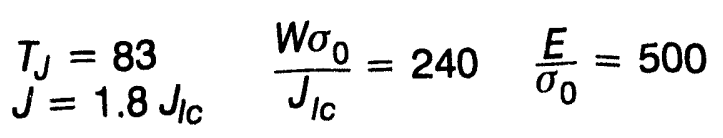

- Steady Growth in SSY [31]

FIG. 7-Effects of growth on crack opening stress in $S E(B)$ specimens. For each a/W, growing cracks and stationary cracks are loaded to the same $J$. 


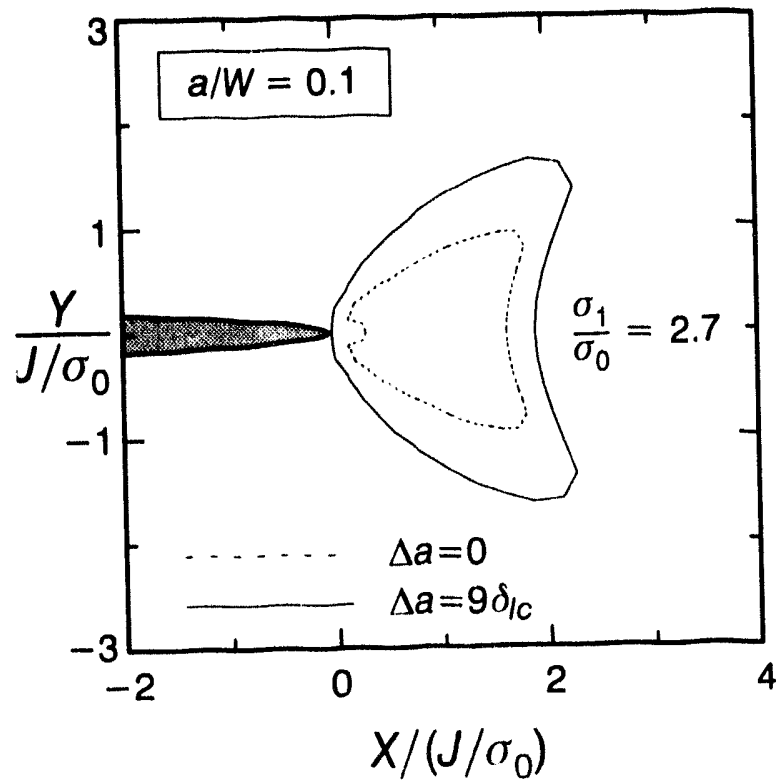

(a)

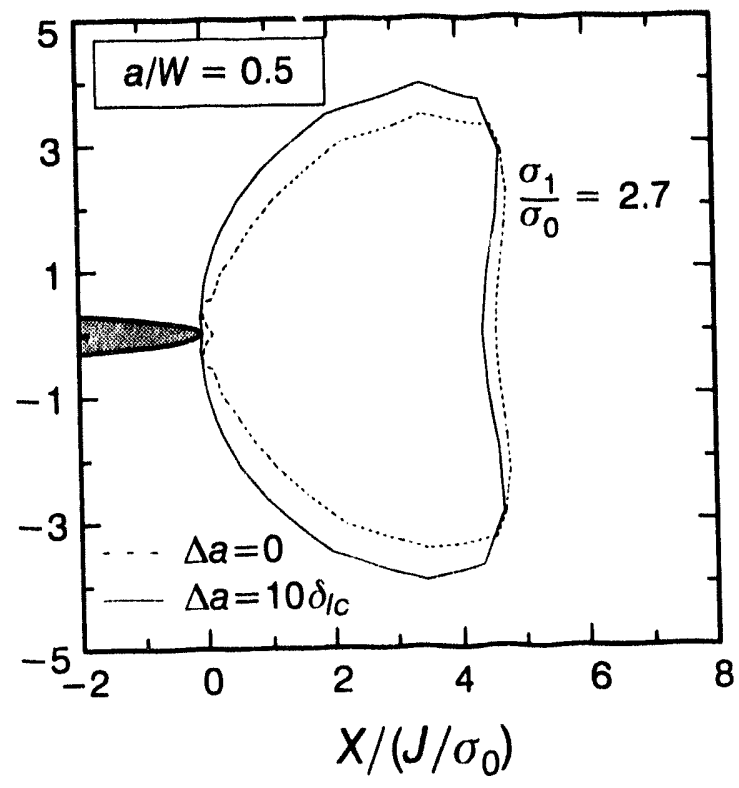

(b)

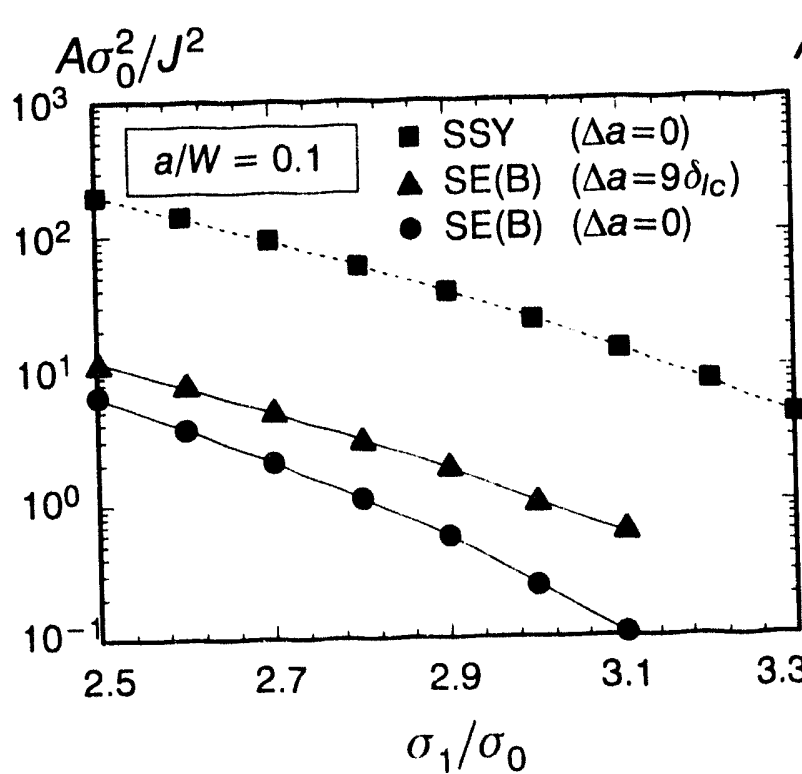

(c)
$A \sigma_{0}^{2} / J^{2}$

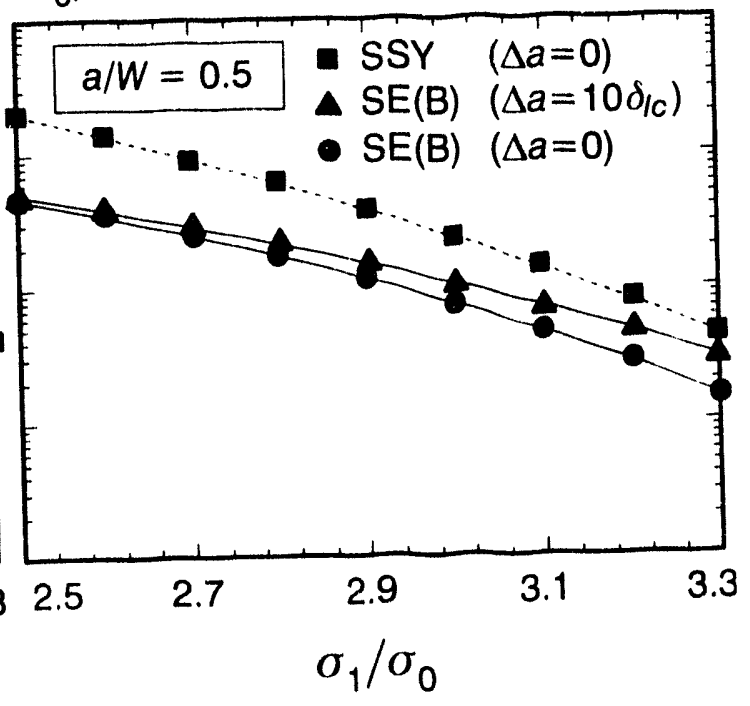

(d)

$$
\begin{aligned}
& T_{J}=83 \\
& n=10
\end{aligned} \quad \frac{W \sigma_{0}}{J_{I c}}=240 \quad \frac{E}{\sigma_{0}}=500
$$

FIG. 8-Effects of crack growth on the instantaneous principal stress contours in $S E(B)$ specimens. For each $a / W$, growing cracks and stationary cracks are loaded to the same J. 
sense the increased peak stress caused by the sharpening. The trends in contour areas shown in these figures are entirely consistent with observations about growth effects on constraint made previously on the basis of crack opening stresses acting on the remaining ligament.

In summary, our extensive studies [30] of SE(B) specimens with crack growth to examine the effects of $n, J_{I c}, T_{J}$ reveal a complex interaction of constraint trade-offs. Increased strain hardening increases the level of constraint and reduces the effect of growth on the near tip fields. Larger values of $J_{l c}$ increase the impact of crack growth on the near-tip stresses - crack growth has more effect when the stress fields at initiation have lost significant constraint relative to SSY. Larger values of the tearing modulus reduce the net change in the constraint due to growth - a large tearing modulus requires large $J$ increases to extend the crack which in-turn accelerate the constraint loss by additional large-scale yielding. Consequently, crack growth has more effect as $T_{J} \rightarrow 0$ and negligible effect as $T_{J} \rightarrow T_{J B L}$ (the blunting line slope).

\section{Tearing Effects on Constraint Model}

The extensive finite element analyses of $\mathrm{SE}(\mathrm{B})$ specimens that include the effects of crack growth provide a basis to extend the previously developed constraint model for cleavage fracture. The SSY stress fields (without crack growth) again define a convenient reference condition to assess constraint effects. The $J_{F B} / J_{0}$ ratios are computed using Eq 8 for trvo $a / W$ ratios $(0.1,0.5)$, for two strain hardening exponents $(n=5,10)$ and for a wide range of values for $J_{I c}$ and tearing modulus. The computations provide $J_{F B} / J_{0}$ ratios based on areas within the instantaneous principal stress contours and on cumulative areas within the envelope of contours constructed over the history of crack growth.

Figures 9 and 10 show the typical variation of $J_{F B} / J_{0}$ ratios with principal stress contour found in the parameter study. These figures illustrate the effects of $a / W$ ratio and hardening exponent for a common value of $J_{I c}$ and $T_{J}$, and also compare the $J_{F B} / J_{0}$ ratios for instantaneous and cumulative areas. The solid lines denote $J_{F B} / J_{0}$ ratios at the onset of crack growth, $J_{F B}=J_{I c}$; each dotted line indicates the ratios at a fixed amount of crack growth. When the $J_{F B} / J_{0}$ ratio increases, constraint (stress triaxiality) in the specimen decreases.

Consider first the shallow crack results shown in Fig. 9. The significant features include: (1) high strain hardening $(n=5)$ limits constraint loss; (2) $J_{F B} / J_{0}$ ratios for crack growth are less dependent on the principal stress ratio than are the ratios for stationary cracks (for $n=10$, the stationary crack has lost similarity of the principal stress contours at $J_{I c}$ ); (3) $J_{F B} / J_{0}$ ratios based on cumulative areas are smaller than ratios based on instantaneous areas, and (4) most importantly, $J_{F B} / J_{0}$ ratios decrease relative to the stationary crack values with increased crack growth and increased loading. This last feature contrasts sharply with the behavior of stationary cracks which show continually increasing $J_{F B} / J_{0}$ ratios under additional loading. Constraint in the shallow crack specimen with $n=10$ increases continuously with crack growth. The response in Fig. 9 (a) for $n=5$ computed using instantaneous areas provides a particularly interesting result in that the constraint remains essentially constant - the increased constraint caused by crack growth cancels almost exactly the constraint loss due to additional plastic deformation under continued loading. 


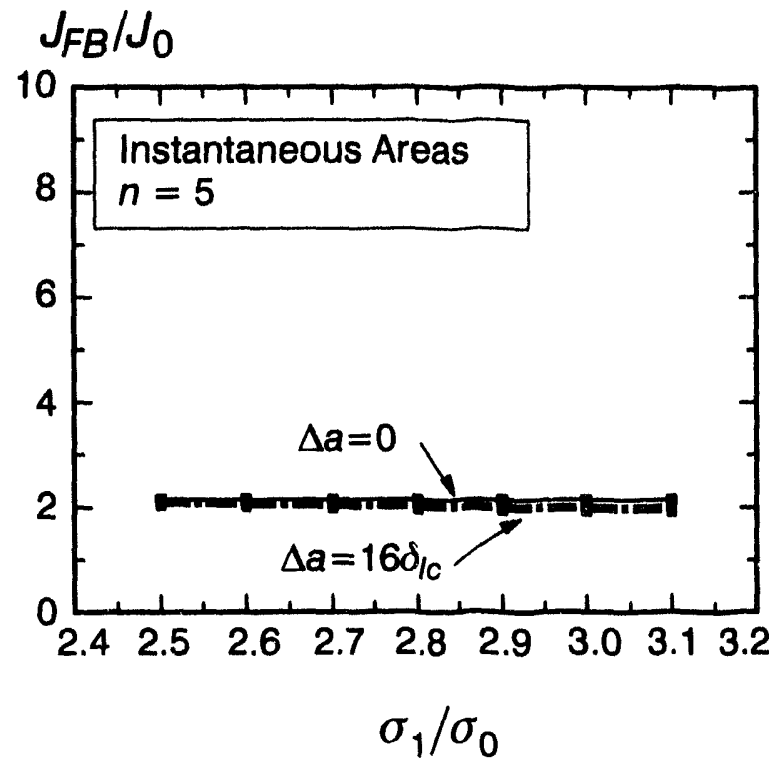

(a)

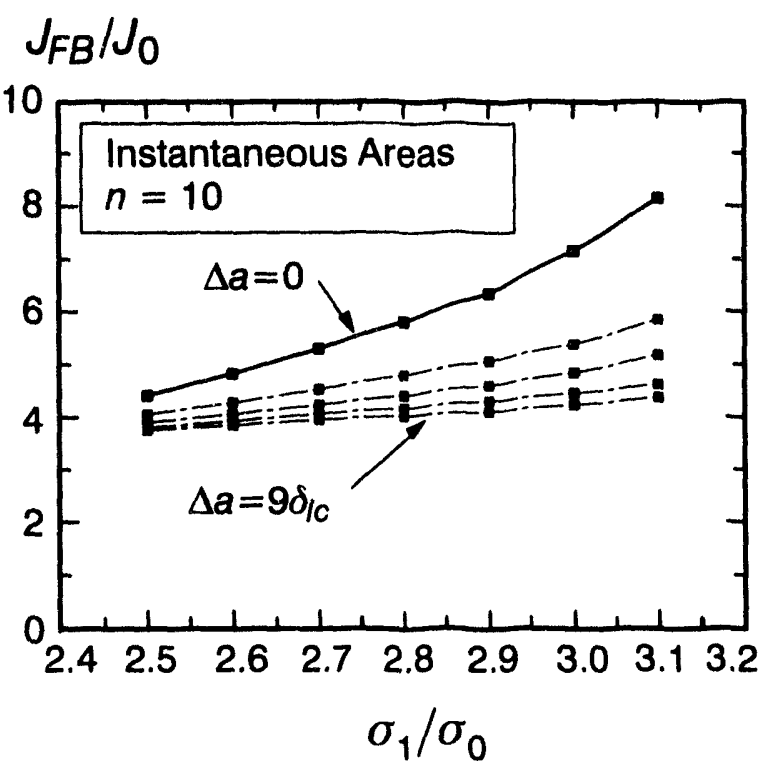

(c)
$J_{F B} / J_{0}$

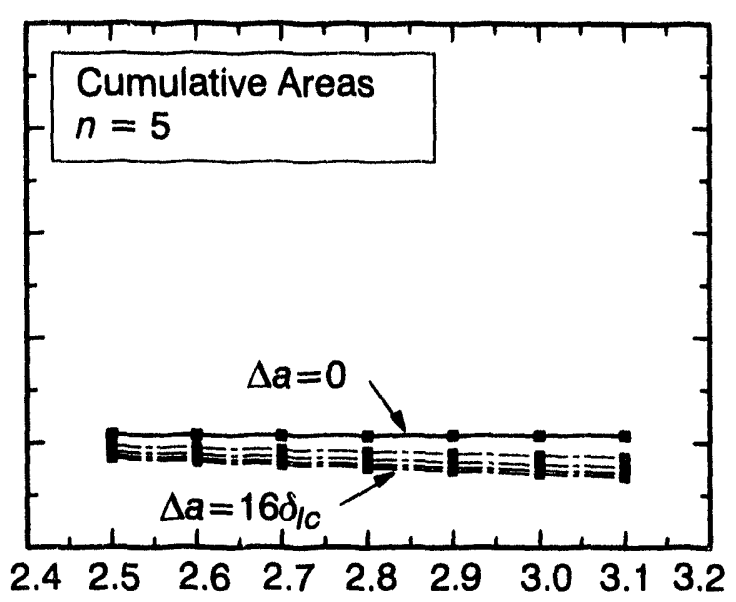

$\sigma_{1} / \sigma_{0}$

(b)

$J_{F B} / J_{0}$

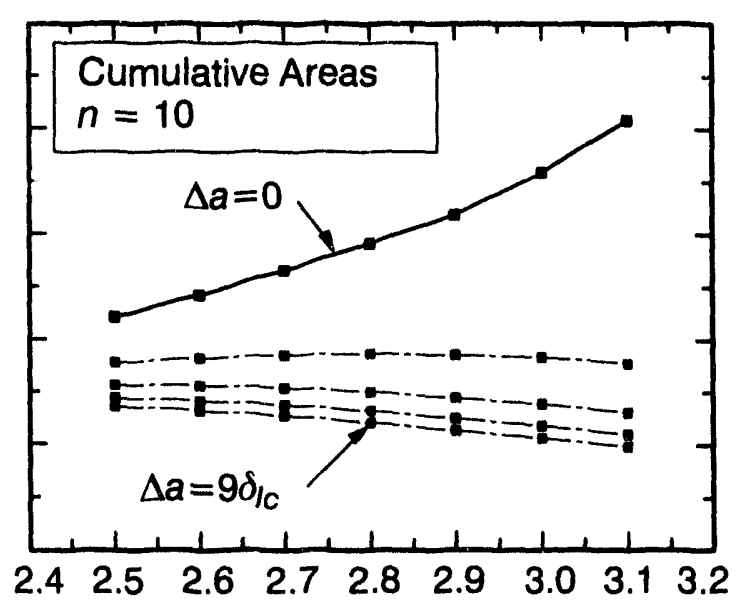

$\sigma_{1} / \sigma_{0}$

$$
\begin{array}{ll}
a / W=0.1 & W \sigma_{0} \\
T_{J}=40 & =240
\end{array} \quad \frac{E}{J_{0}}=500
$$

FIG. 9-Effects of principal stress ratio and instantaneous vs. cumulative areas on $J_{0}$ for a shallow-notched $S E(B)$ specimen $(a / W=0.1)$. 


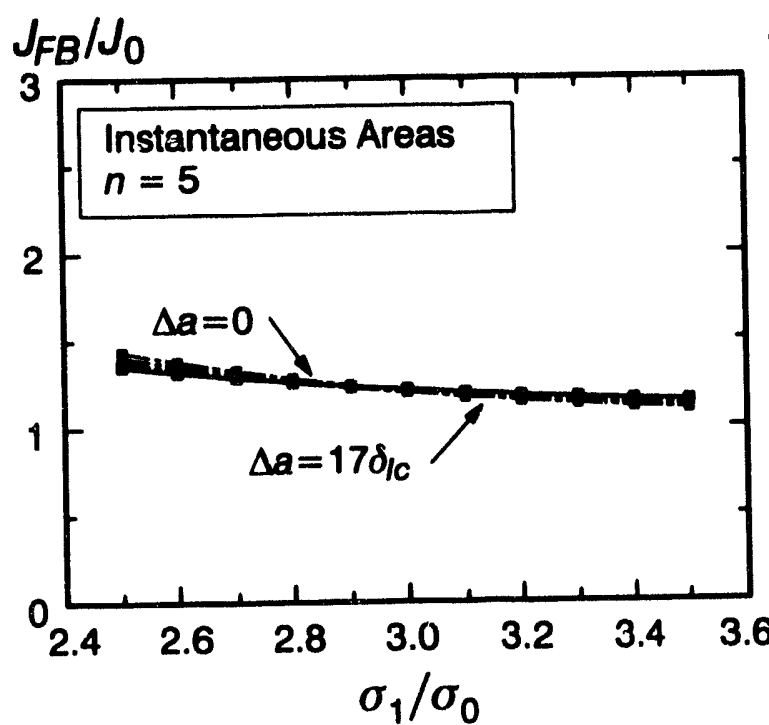

(a)

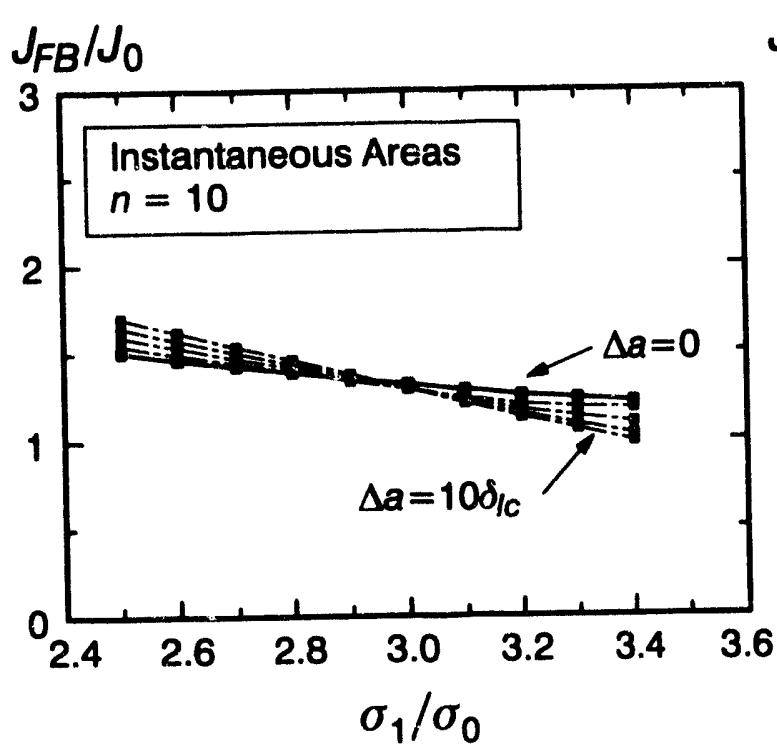

(c) $J_{F B} / J_{0}$

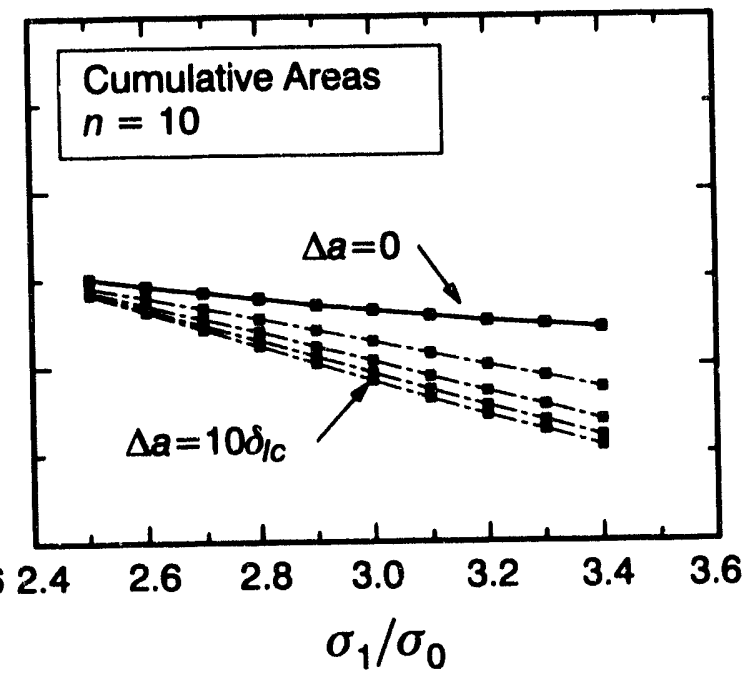

(d)

$$
\begin{array}{lll}
a / W=0.5 & W \sigma_{0} \\
T_{J}=: 40 & =240 & \frac{E}{\sigma_{0}}
\end{array}=500
$$

FIG. 10-Effects of principal stress ratio and instantaneous vs. cumulative areas on $J_{0}$ for a deep-notched $S E(B)$ specimen $(a / W=0.5)$. 
Consider next the deep crack results shown in Fig. 10. The overall trends remain similar except: (1) $J_{F B} / J_{0}$ ratios at the onset of tearing are weakly dependent on the principal stress ratio for both low and high amounts of hardening and (2) $J_{F B} / J_{0}$ ratios for growth based on cumulative area for $n=10$ show a more noticeable dependence on the principal stress contour. During crack growth with the corresponding increase in $J$, the specimen deformation increases substantially and the bending field impinges on the crack-tip region.

Figure 11 recasts these $J_{F B} / J_{0}$ ratios for $\sigma_{1} / \sigma_{0}=2.7$ into the usual format of the constraint model. Results of similar computations for additional values of $J_{I c}$ are given as well. Solid lines denote the stationary crack response while dashed lines denote the growth response in terms of the instantaneous and cumulative contour areas. Each curve for the specific $a / W$ ratio terminates at the same amount of crack growth in the specimen ( $\Delta a_{\max }$ is indicated for each set of results). A reference line indicating $\Delta J_{0}=\Delta J_{F B}$ is provided on the figures to aid in assessing the relative constraint changes.

On these and subsequent figures, we normalize $J$-quantities using the flow stress $\left(\sigma_{\text {flow }}\right)$ rather than $\sigma_{0}$ to make the results less sensitive to the actual estimate of the hardening exponent. For a Ramberg-Osgood material representation used in the finite element computations, an estimate for the flow stress is given by

$$
\sigma_{\text {flow }}=\frac{\sigma_{0}}{2}\left[1+\frac{\left(N / \varepsilon_{0}\right)^{N}}{\exp (N)}\right]
$$

where $N=1 / n$. The remaining ligament prior to crack growth, $b=W-a_{0}$, provides a suitable specimen dimension for normalizing $J$ in the constraint model.

This figure shows clearly the effects of crack growth on the effective $J$ for cleavage fracture $\left(J_{0}\right)$ for increasing $J_{I c}$ at a common value of the tearing modulus $\left(T_{J}=40\right)$. All dashed lines in Fig. 11 lie above the solid lines, which indicate constraint increases with crack growth. Significant observations from this figure include: (1) the constraint model using the cumulative areas always predicts larger values of effective fracture driving force $\left(J_{0}\right) ;(2)$ the greater impact of growth for the shallow crack specimens is apparent by the much sharper deviation of the growth curves from the stationary crack curve; (3) for this combination of material parameters, the cumulative growth curves have slopes of $\approx 1$, i.e., increments of $J_{F B}$ applied to the specimen after the onset of growth are transmitted fully into increments of increased driving force for cleavage.

\subsection{Normalizing $J_{\text {Ic }}$ Effects}

Figure 11, and others constructed for a range of tearing modulus values, provides the motivation for development of a normalization procedure to minimize the dependence of the model on values of $J_{I c}$. The family of growth constraint curves for different values of the tearing modulus (at a common $J_{I c}$ ) simply translates with increased values for $J_{I c}$ while retaining a nearly constant orientation relative to the gradient of the constraint curve for the stationary crack. Figure 12 (a-b) demonstrate the effects of $J_{I c}$ on the growth portions of the constraint model when viewed in this framework. In Fig. 12 (a), $m$ represents the gradient of the stationary-crack constraint model at $J_{I c}, m=d J_{0} / d J_{F B}$; $\alpha$ denotes the angle change between the tangent line to the stationary curve (which has slope $m$ ) and a similar line drawn tangent to the growth curve at the same $J_{I c}$ value. When the $J_{I c}$ value increases from 


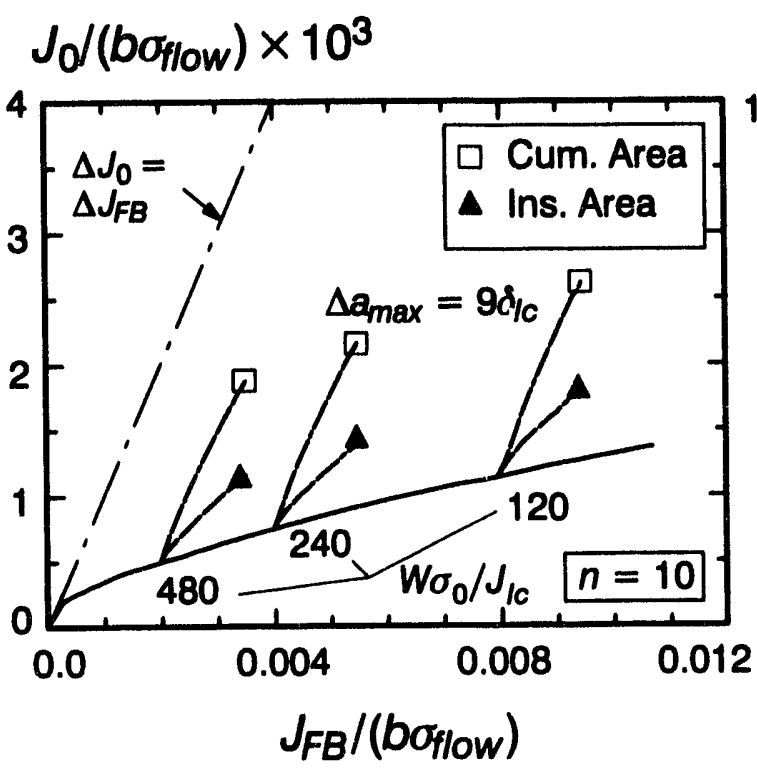

(a) $a / W=0.1$
$J_{0} /\left(b \sigma_{\text {flow }}\right) \times 10^{3}$

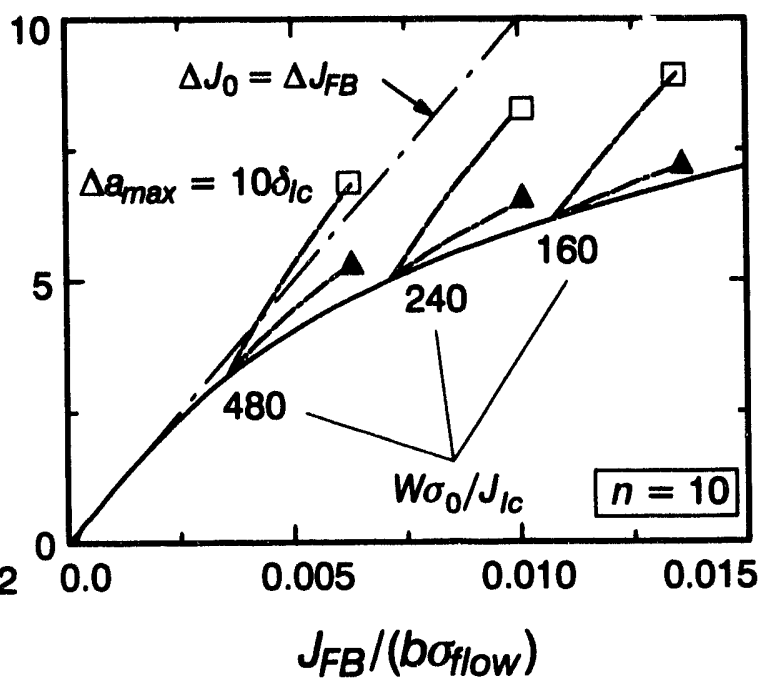

(b) $a / W=0.5$

FIG. 11-Comparison of constraint corrections for growth based on areas enclosed within instantaneous and cumulative principal stress contours for $S E(B)$ specimens $\left(T_{J}=40, \sigma_{1} / \sigma_{0}=2.7\right)$.

$J_{I c}^{(1)}$ to $J_{l f}^{(2)}, m$ decreases significantly from $m_{1}$ to $m_{2}$ as indicated on the figure. Figure 13 provides values of $m$ for SE(B) specimens containing shallow and deep cracks for hardening exponents $n=5,10$.

Figure 12 (b) shows growth curves defined at increasing values of $J_{I c}$ after the applicable $J_{I c}$ value is subtracted from the total values of $J_{F B}$ and $J_{0}$. The shifted curves now show only the increments of $J$ that occur during growth, denoted $\Delta J_{F B}$ and $\Delta J_{0}$, and defined by:

$$
\begin{aligned}
& \Delta J_{F B}=J_{F B}-J_{I c} \\
& \Delta J_{0}=J_{0}-J_{0}^{I c}
\end{aligned}
$$

where, for the remainder of this section, all $J$-quantities are implicitly normalized by the applicable $b \sigma_{\text {flow }} ; J_{0}^{I c}$ represents the value of $J_{0}$ at $J_{F B}=J_{I c}$. Using these new quantities, the nearly equal values of $a$ at the different values of $J_{I c}$ become more apparent. The $a$ values exhibit a weak dependence on $J_{I c}$ for the $a / W=0.5$ specimen, but are strongly independent of $J_{I c}$ for the $a / W=0.1$ specimen. Since $a$ remains relatively constant, the dependence of the growth curves with $J_{l c}$ may be approximated as a linear function of the gradients $(m)$ for the stationary crack.

A simple procedure now defines the relationship between $J_{0}$ values for two different $J_{I c}$ values. Consider points $A$ and $B$ in Fig. 12 (a) which represent specimens with the same $T_{J}$ and same (normalized) amount of crack growth but with different (normalized) $J_{I c}$ values - configurations (1) and (2) thus may represent specimens differing in absolute size but having the same absolute value of $J_{I c}$. The constraint corrected values for these two points are labelled $J_{0}^{A}$ and $J_{0}^{B}$ in Fig. 12 (a). During crack growth along (2) to reach point $B, J_{F B}$ changes by $\Delta J_{F B}^{B}=\Delta J_{F B}$; for growth along (1) to reach $A$ the change in $\Delta J_{F B}^{A}$ is also $\Delta J_{F B}\left(T_{J}\right.$ and $\Delta a$ are the same). The 


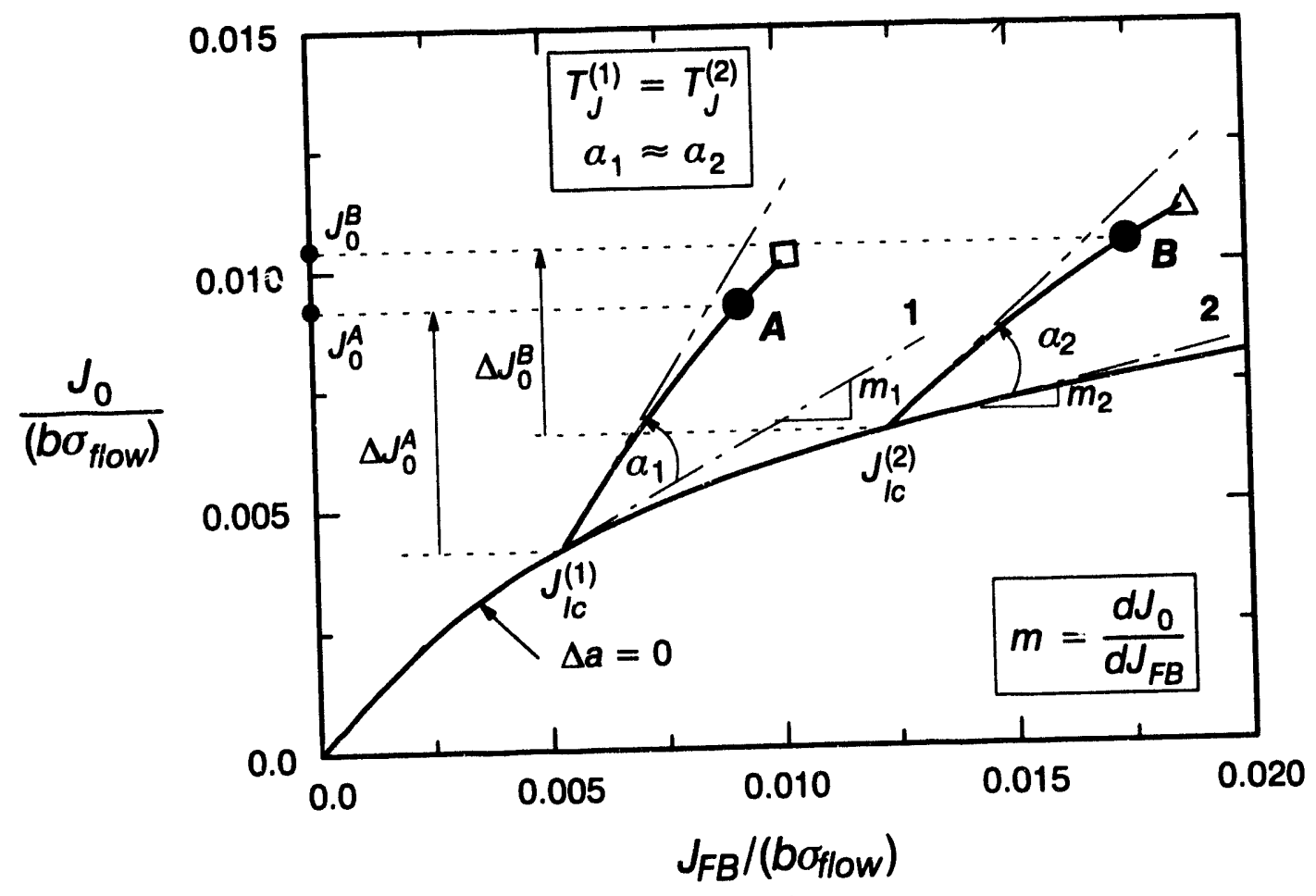

(a)

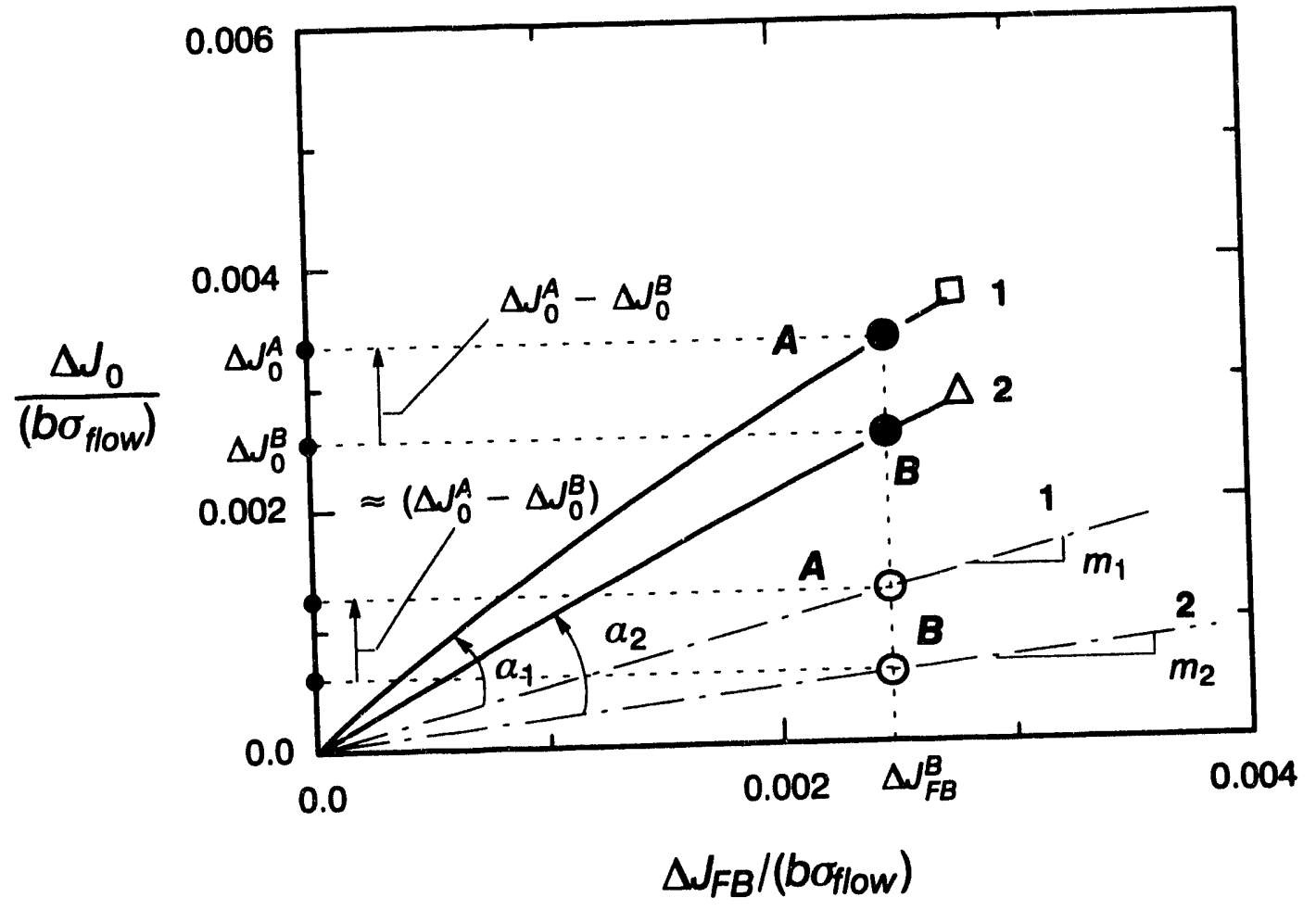

(b)

FIG. 12-Development of approximate normalization scheme to minimize dependence of growth constraint model on absolute values of $J_{I c}$. 


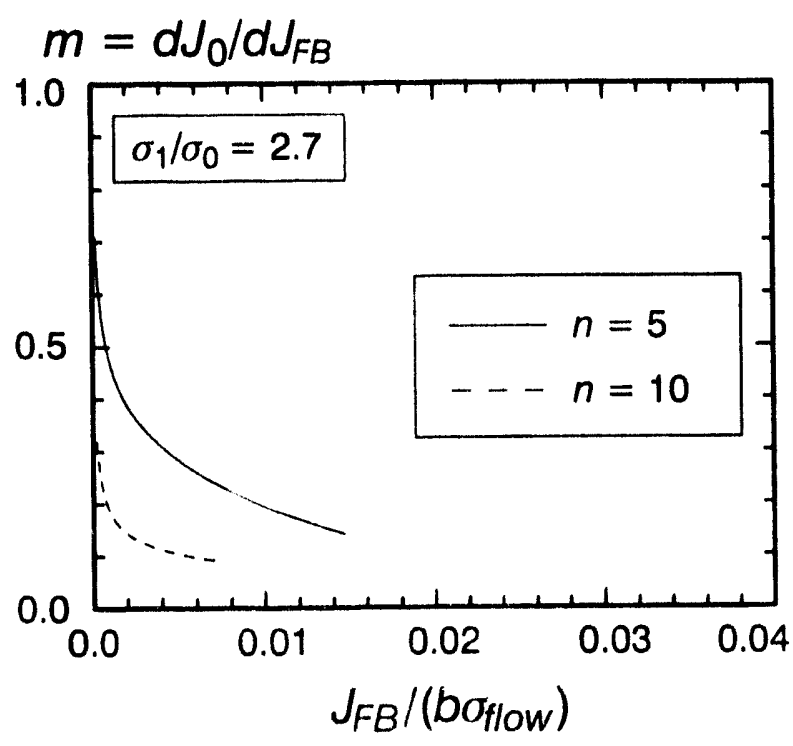

(a) $a / W=0.1$

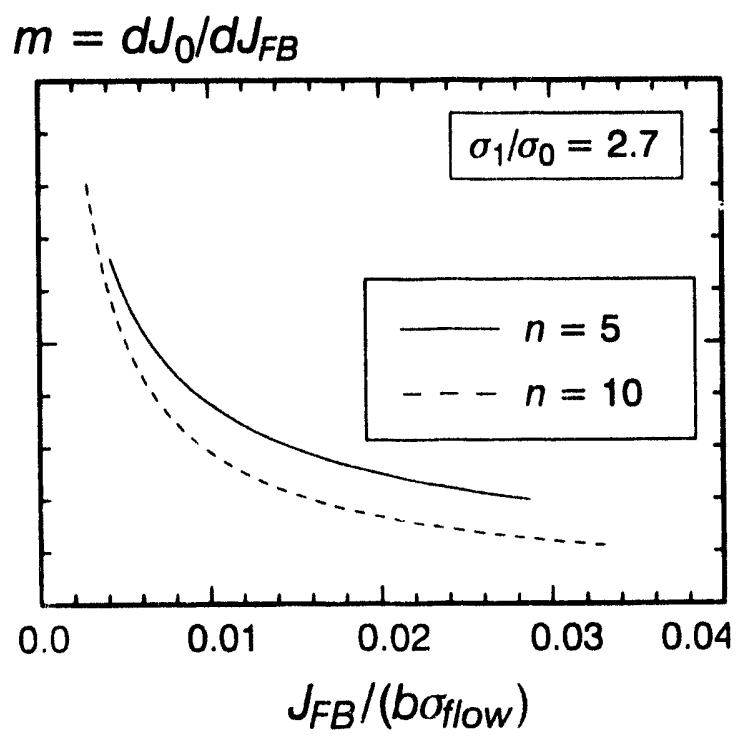

(b) $a / W=0.5$

FIG. 13-Gradients $(m)$ for stationary constraint models of $S E(B)$ specimens $\left(a / W=0.1,0.5 ; n=5,10 ; E / \sigma_{0}=500\right)$.

corresponding changes in $J_{0}$ values during growth are shown as $\Delta J_{0}^{A}$ and $\Delta J_{0}^{B}$. Using the approximation that $\alpha_{1} \approx \alpha_{2}$, Fig. $12(\mathrm{~b})$ illustrates that the difference between $\Delta J_{0}^{A}$ and $\Delta J_{0}^{B}$ may be given by the expression:

$$
\Delta J_{0}^{A}-\Delta J_{0}^{B} \approx \Delta J_{F B} \cdot\left(m_{1}-m_{2}\right)
$$

Using this relationship, the constraint corrected value for point $A$ may be expressed in terms of the constraint corrected value for point $B$ as (solve above expression for $\left.\Delta J_{0}^{A}\right)$

$$
J_{0}^{A}=J_{0}^{I c(1)}+\Delta J_{0}^{A} \approx J_{0}^{I c(1)}+\Delta J_{0}^{B}+\Delta J_{F B} \cdot\left(m_{1}-m_{2}\right) .
$$

Again,all $J$ quantities in this expression are understood to be normalized by the applicable value of $b \sigma_{f l o w}$.

For interpretation of experimental data, the corrected toughness value, $J_{0}$, is sought given measured values for $J_{F B}$ and $\Delta a$ at fracture, in addition to estimated values for $J_{I c}$ and the tearing modulus. To develop more useful expressions, it proves convenient to define a common reference position on the stationary crack curves. We selected the position where the gradient of the stationary curve equals unity, $m_{\text {ref }}=1$.

The growth portion of each constraint model curve, $\Delta J_{0}$, is normalized to define $\Delta \bar{J}_{0}$ at the reference position using

$$
\Delta \bar{J}_{0}=\Delta J_{0}+\Delta J_{F B} \cdot\left(1-m_{I c}\right)
$$

where $m_{I c}$ denotes the gradient of the stationary curve at $J_{I c}$ for the specific configuration. Figures 14 and 15 summarize results for all the $S E(B)$ analyses $(a / W=0.1$, $0.5 ; n=5,10$ ) for each of the $J_{I c}$ and tearing modulus values using both definitions for computation of the growth crack curves (instantaneous and cumulative areas). Figure 16 provides similar results for much larger selected values of tearing modulus. 


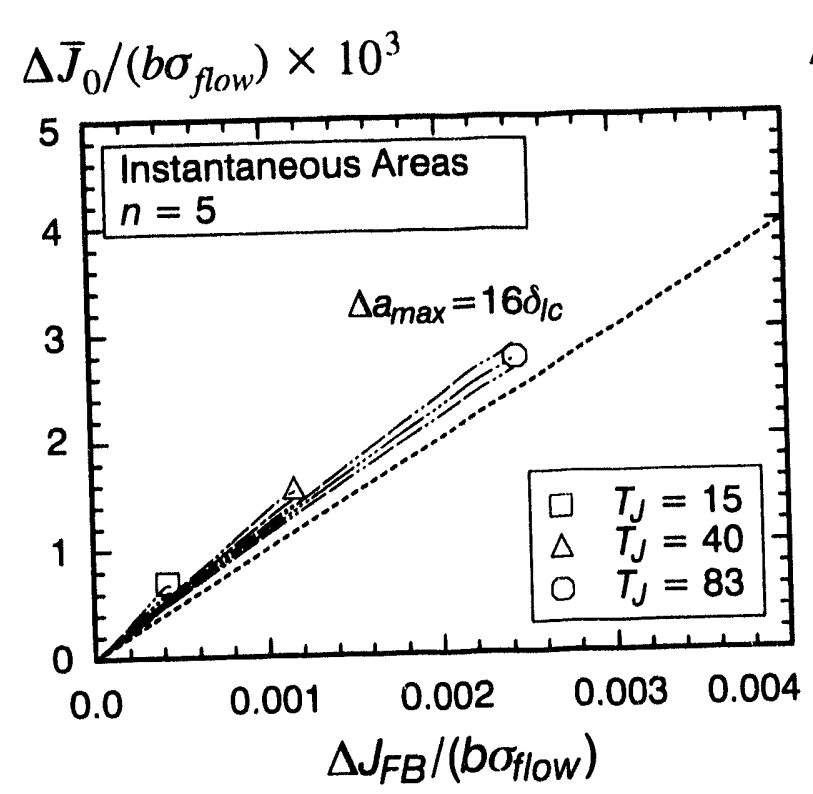

(a)

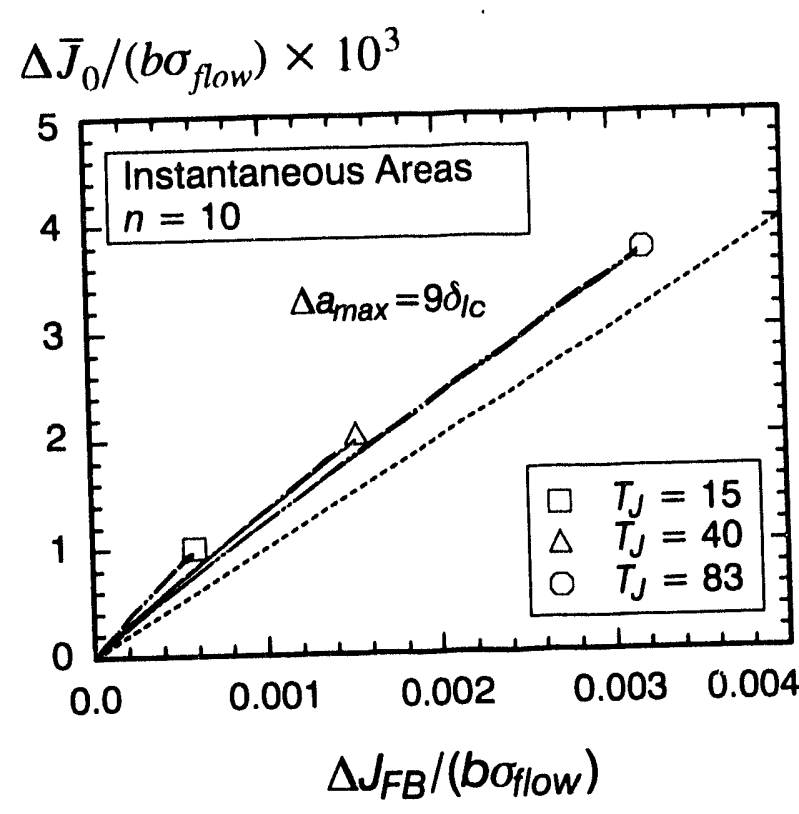

(c)
$\Delta \bar{J}_{0} /\left(b \sigma_{\text {flow }}\right) \times 10^{3}$

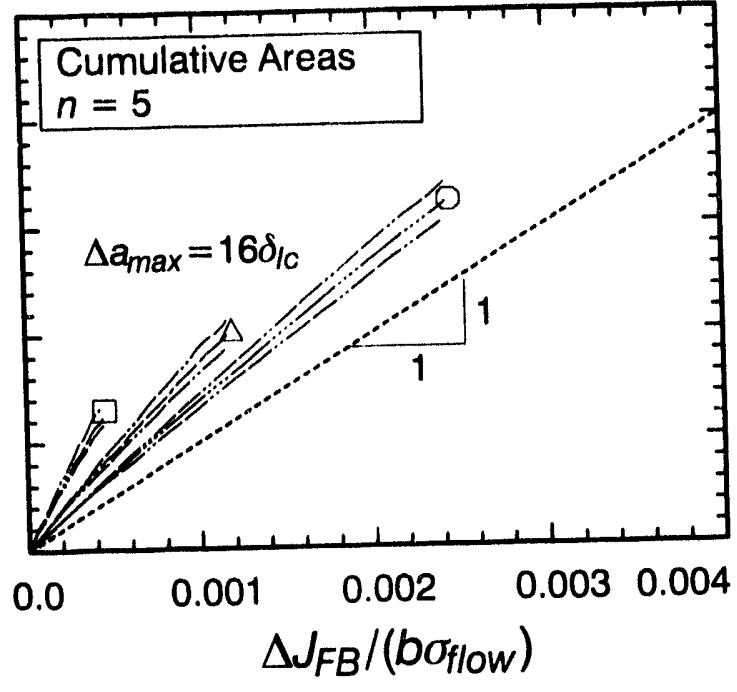

(b)

$\Delta \bar{J}_{0} /\left(b \sigma_{\text {flow }}\right) \times 10^{3}$

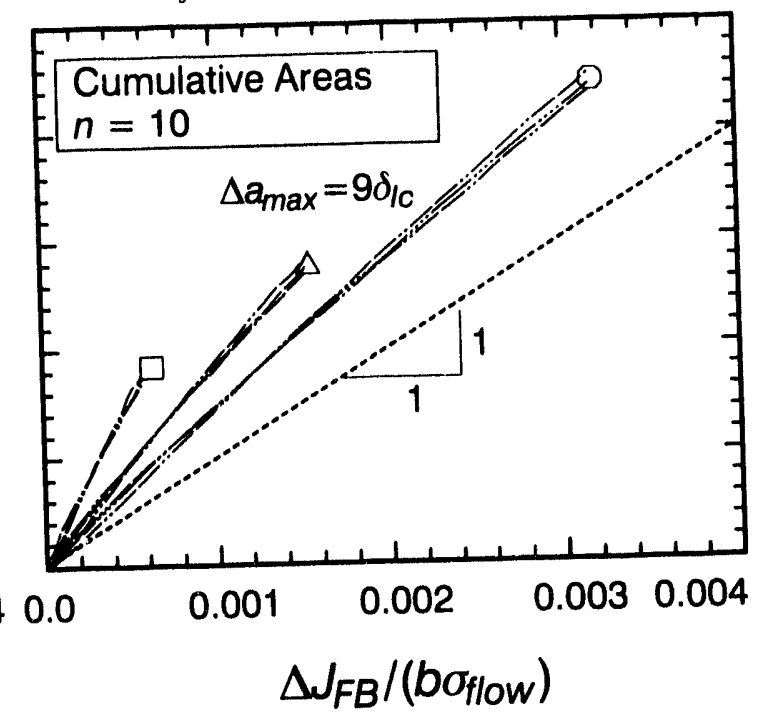

(d)

$$
a / W=0.1 \quad \frac{\sigma_{1}}{\sigma_{0}}=2.7 \quad \frac{E}{\sigma_{0}}=500
$$

FIG. 14-Growth portion of constraint model normalized to reference point on stationary crack solution for $S E(B)(a / W=0.1 ; n=5,10)$. 
The normalization using Eq 15 accomplishes the intended purpose of minimizing the dependence on $J_{I c}$ for growth curves having a common tearing modulus. Our analyses also indicate a weak dependence of $\Delta \mathcal{J}_{0}$ on $\sigma_{1} / \sigma_{0}$ over the range $2.5 \leq \sigma_{1} / \sigma_{0} \leq 3.1$.

Equations 14 and 15 are combined to yield the final expression for $J_{0}$ needed to correct experimentally measured toughness values. Deleting the notation of configurations (1), (2) and the notion of a specific point $A$ from Eq 14, a more general expression is given by

$$
J_{0}=J_{0}^{I c}+\Delta J_{0} \text {. }
$$

(Figure 12 (a) provides the graphical interpretation of this expression). Equation 15 is solved for $\Delta J_{0}$ and the result substituted into the above relationship to define

$$
\frac{J_{0}}{b \sigma_{\text {flow }}} \approx \frac{J_{0}^{I c}}{b \sigma_{\text {flow }}}+\frac{\Delta \bar{J}_{0}}{b \sigma_{\text {flow }}}-\frac{\Delta J_{F B}}{b \sigma_{\text {flow }}} \cdot\left(1-m_{l c}\right)
$$

where normalization of all $J$-quantities by the initial remaining ligament $\left(b=W-a_{0}\right)$ and the flow stress is indicated.

Although not explicitly used here, we note the strong linear dependence of $\Delta \bar{J}_{0}$ with $\Delta J_{F B}$ which may lead to development of useful expressions of the form

$$
\Delta \bar{J}_{0} \approx \mathcal{H}\left(n, \frac{a}{W}, T_{J}\right) \Delta J_{F B}
$$

where tabular or curve fit values for $\mathcal{H}$ can be derived from Figs. 14 and 15.

The following procedure summarizes the application of Eq 17 to correct experimental measures of fracture toughness:

\section{Quantities needed:}

- measured or inferred values for $n, \sigma_{f l o w}, J_{I c}, T_{J}$

- measured $J$ at cleavage fracture $\left(J_{F B}\right)$

\section{Steps in procedure:}

1. compute $\Delta J_{F B}=J_{F B}-J_{I c}$

2. look up $\Delta \bar{J}_{0}$ using $\Delta J_{F B}$ in the graphs provided in Figs. 14 and 15

3. look up $m$ for $J_{F B}=J_{I c}$ using graphs in Fig. 13

4. evaluate $J_{0}^{I c}$ using the constraint correction curves for the stationary crack ( $J_{0}^{I c}$ is $J_{0}$ evaluated at $J_{I c}$; Fig. 1 provides stationary crack solutions.)

5. evaluate $J_{0}$ by substituting the above quantities into Eq 17

Note: The experimental estimates for $J_{I c}$ used in this procedure should be obtained by projecting early parts of the $R$-curve back to a suitable blunting line, not to a $0.2 \mathrm{~mm}$ offset line, to be consistent with the finite element interpretation of $\Delta a$.

The constraint model including crack growth expressed by Eq 17 and associated figures retains the essential features of original Dodds-Anderson model. This engineering model captures the key features of the phenomenon in a straightforward approach. Application of the new model to correct experimental values of fracture toughness for constraint involves only two new steps compared to the model without crack growth.

\subsection{Application of Constraint Model Including Crack Growth}

Experimental data consisting of $J_{R}-\Delta a$ values $[12,17]$ that terminate in cleavage fracture are presented Figures 17 and 18 for two materials, A515 plate and sub- 
$\Delta \bar{J}_{0} /\left(b \sigma_{\text {flow }}\right) \times 10^{3}$

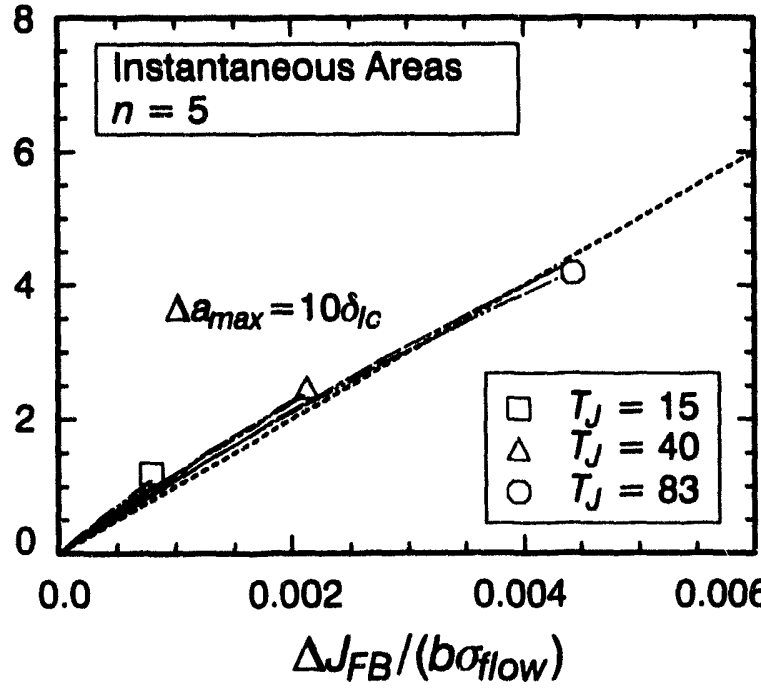

(a)
$\Delta \bar{J}_{0} /\left(b \sigma_{\text {flow }}\right) \times 10^{3}$

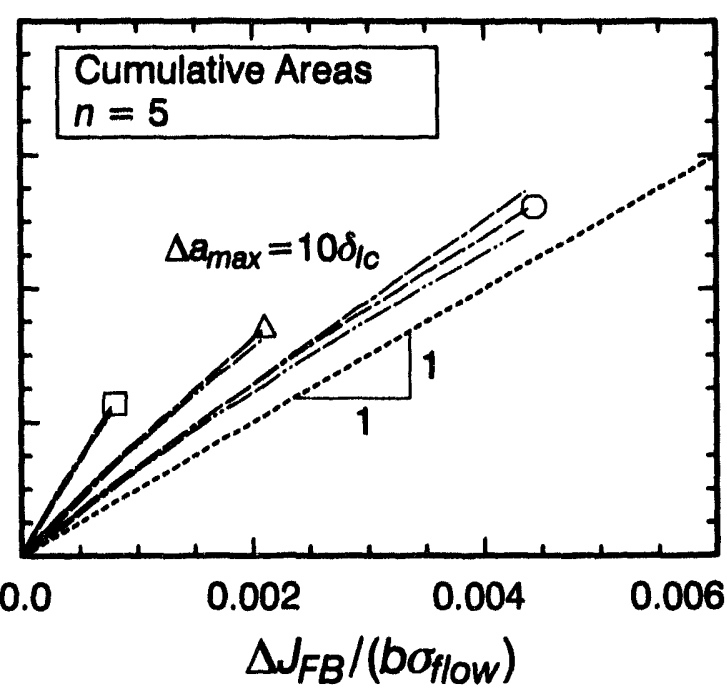

(b)

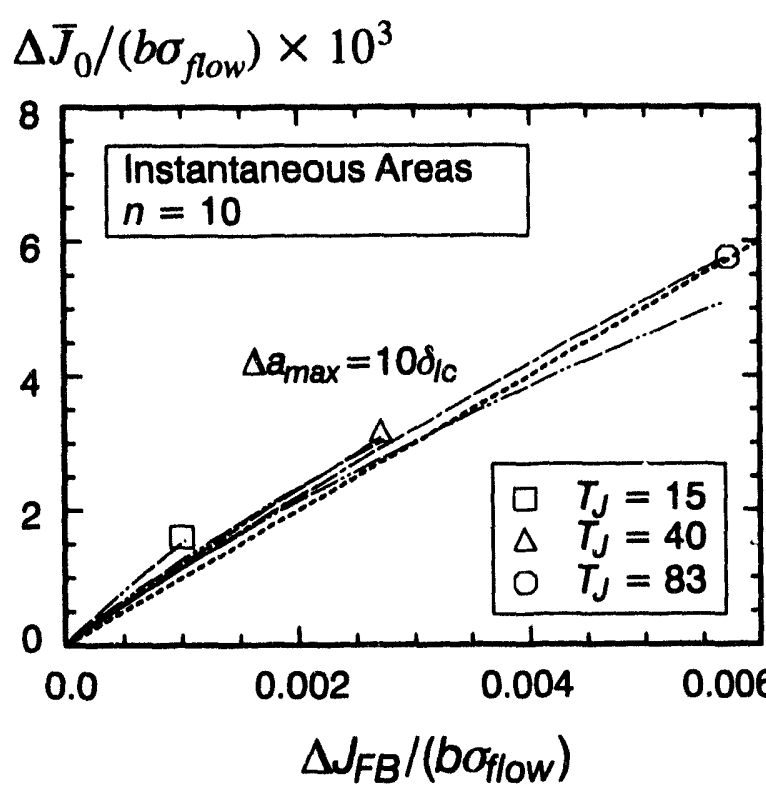

(c)
$\Delta \bar{J}_{0} /\left(b \sigma_{\text {flow }}\right) \times 10^{3}$

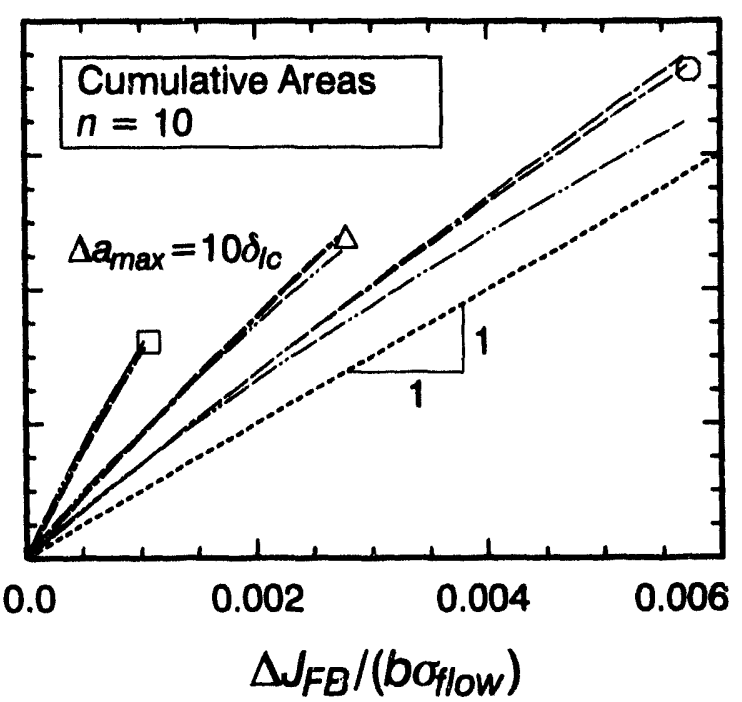

(d)

$$
a / W=0.5 \quad \frac{\sigma_{1}}{\sigma_{0}}=2.7 \quad \frac{E}{\sigma_{0}}=500
$$

FIG. 15-Growth portion of constraint model normalized to reference point on stationary crack solution for $S E(B)(a / W=0.5 ; n=5,10)$. 


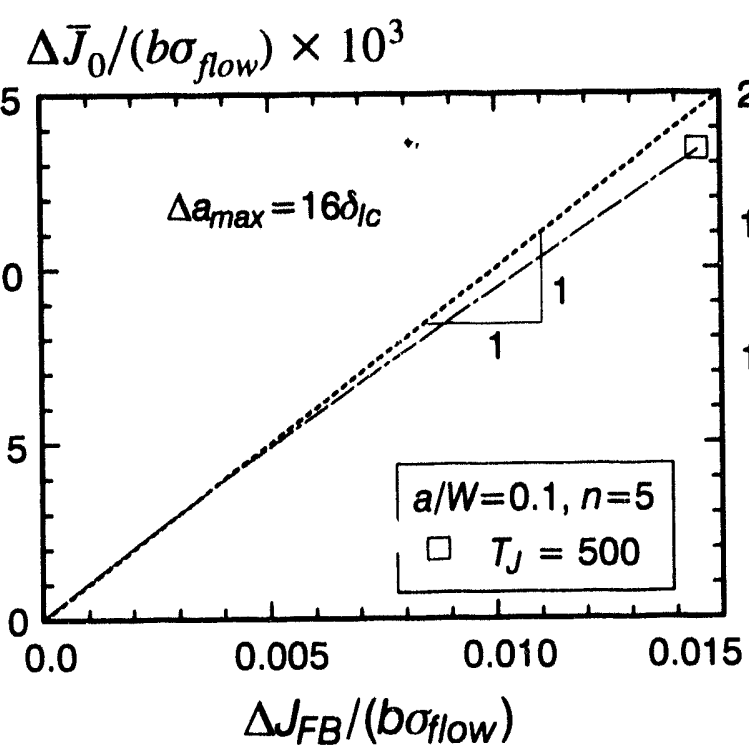

(a)

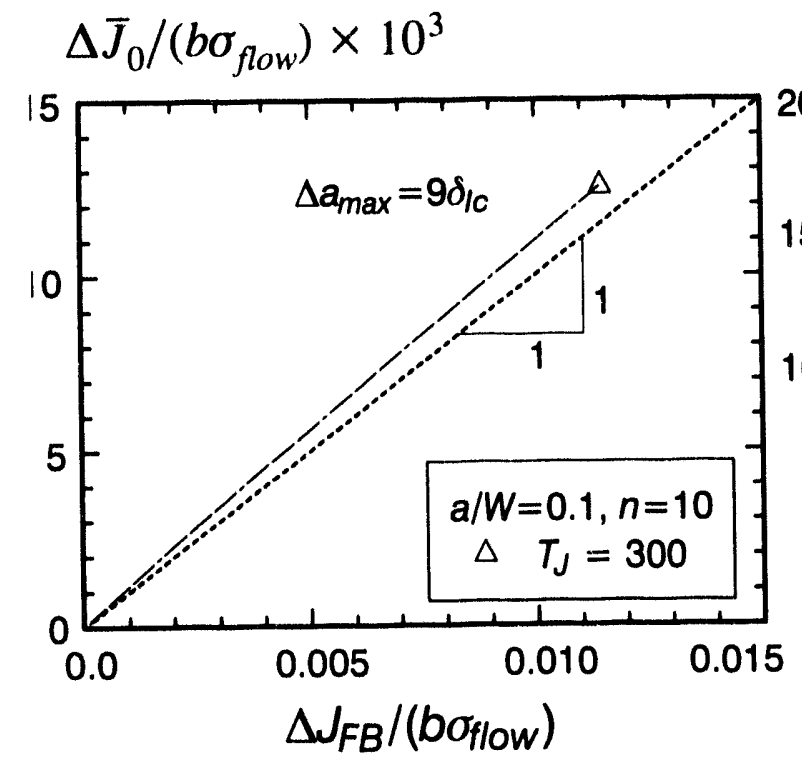

(c)
$\Delta \bar{J}_{0} /\left(b \sigma_{\text {flow }}\right) \times 10^{3}$

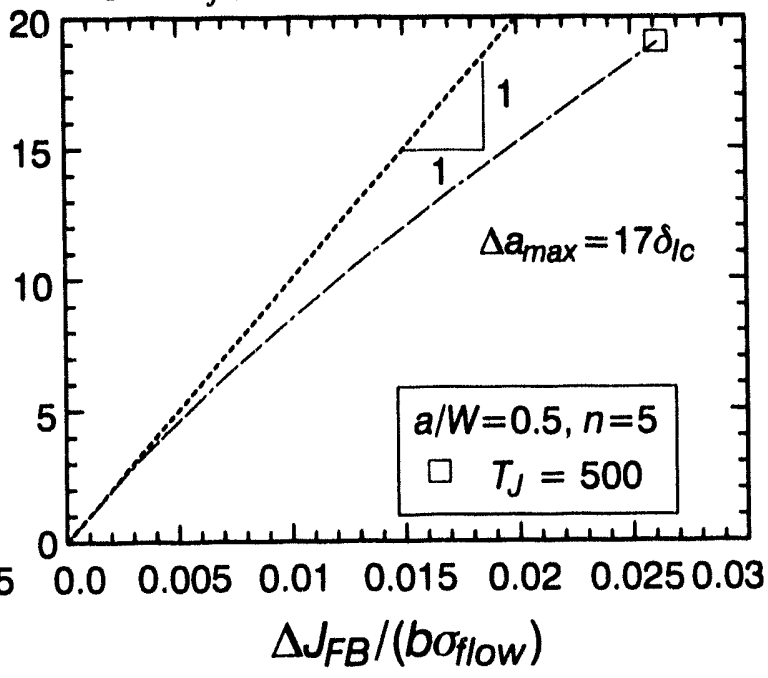

(b)
$\Delta \bar{J}_{0} /\left(b \sigma_{\text {flow }}\right) \times 10^{3}$

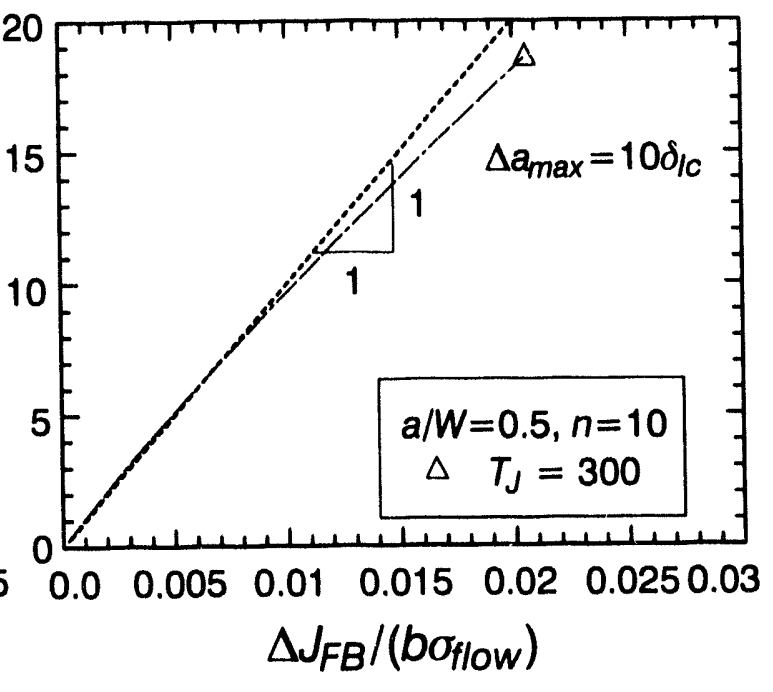

(d)

$$
\underset{\text { Areas }}{\text { Cumulative }} \quad \frac{\sigma_{1}}{\sigma_{0}}=2.7 \quad \frac{E}{\sigma_{0}}=500
$$

FIG. 16-Growth portion of constraint scaling model normalized to reference point on stationary crack solution for $S E(B)(a / W=0.1 ; n=5,10$, high tearing 
merged arc welds in A533B. The A515 data set [12] was produced by testing SE(B) specimens $(a / W=0.1)$ while the A533B data set [17] was produced by testing $C(T)$ specimens with $a / W=0.5$. The $C(T)$ specimens are analyzed here using computational results for the deep-notch $S E(B)$ specimen. Table 1 summarizes the material properties and testing conditions. Estimates for $J_{I c}$ and for the constant value of tearing modulus indicated in the table are found by fitting the experimental data (note the maximum amount of ductile crack extension is 6\% of $b_{0}$ for the A533B tests and $25 \%$ of $a_{0}$ for the A515 tests). The rightmost column in Table 1 shows the ratio of the tearing modulus to the the slope of the blunting line expressed as a tearing modulus. Specific finite element analyses were performed for these configurations to accommodate the actual tearing modulus for construction of the constraint model.

\begin{tabular}{|c|c|c|c|c|c|c|c|c|}
\hline $\begin{array}{c}\text { Sources of Test } \\
\text { Results }\end{array}$ & $\begin{array}{c}\text { ASTM } \\
\text { Steel }\end{array}$ & $\begin{array}{c}\text { Temp. } \\
{\left[{ }^{\circ} \mathrm{C}\right]}\end{array}$ & $n$ & $\begin{array}{c}\sigma_{y s} \\
{[\mathrm{MPa}]}\end{array}$ & $\begin{array}{c}\sigma_{u t s} \\
{[\mathrm{MPa}]}\end{array}$ & $\begin{array}{c}J_{I c} \\
{\left[\mathrm{~kJ} / \mathrm{m}^{2}\right]}\end{array}$ & $T_{J}$ & $\frac{T_{J}}{T_{J B L}}$ \\
\hline McCabe [17] & $\begin{array}{c}\mathrm{A5338-G} \\
1\end{array}$ & $-15 \& 0$ & 10 & 503 & 627 & 75 & 287 & 0.35 \\
\hline Kirk, et al [12] & $\mathrm{A515-G70}$ & 20 & 5 & 296 & 545 & 88 & 420 & 0.30 \\
\hline
\end{tabular}

Table 1-Values of $J_{I c}$ and $T_{J}$ obtained by fitting experimental toughness values

Figures 17 (a) and 18 (a) compare measured toughness values expressed as $J_{R}-\Delta a$ curves with constraint corrected $\left(J_{0}\right)$ values obtained for each data point. Filled squares denote measured toughness values (uncorrected). Filled triangles denote $J_{c}$-values corrected only for large-scale yielding effects and circles denote $J_{c}$-values corrected for both large-scale yielding and crack growth effects. $J_{0}$-values including growth corrections are provided for the model derived from the instantaneous stress fields ahead of the growing crack and for the model derived from cumulative areas within the envelope of principal stress contours. $J_{0}$-values based on the cumulative areas are always larger - they include area contributions over which the principal stress equaled or exceeded the specified value during the history of growth.

The correction for large-scale yielding reduces the largest measured $J_{c}$-values by approximately a factor of three for the deep-notch data set, see Fig. 17 (a), and by a factor approaching five for the shallow-notch specimens, see Fig. 18 (a). Relative to the constraint model for large-scale yielding, the new model which includes both growth and large-scale yielding increases the effective fracture toughness $\left(J_{0}\right)$ by approximately 25-30\% for the deep-notch (A533B) specimens with almost no increase due to growth predicted for the shallow-notch (A515) specimens. The A515 data set has a large tearing modulus and a high degree of strain hardening which combine to suppress any increased constraint from crack growth. In this data set, $W \sigma_{0} / J_{I c}=170$ and $J_{I c} / J_{0} \approx 2.2$; the $J_{F B} / J_{0}$ increases to $\approx 5$ at the last data point. For comparison, Fig. 9 (a) shows the response of an $\mathrm{SE}(\mathrm{B})$ specimen with $a / W=0.1$ and $n=5$ but with a much smaller tearing modulus $\left(T_{J}=40\right.$ vs. 420 for the A515 material) and smaller deformation at the onset of tearing $\left(W \sigma_{0} / J_{I c}=240 \mathrm{vs} .170\right.$ for the A515 material). In that case, crack growth maintains constraint constant at $J_{F B} / J_{0}$ $\approx 2$ under increased loading which implies that during crack growth $\Delta J_{F B}=\Delta J_{0}$; for the A515 data set, $\Delta J_{F B}>\Delta J_{0}$. 


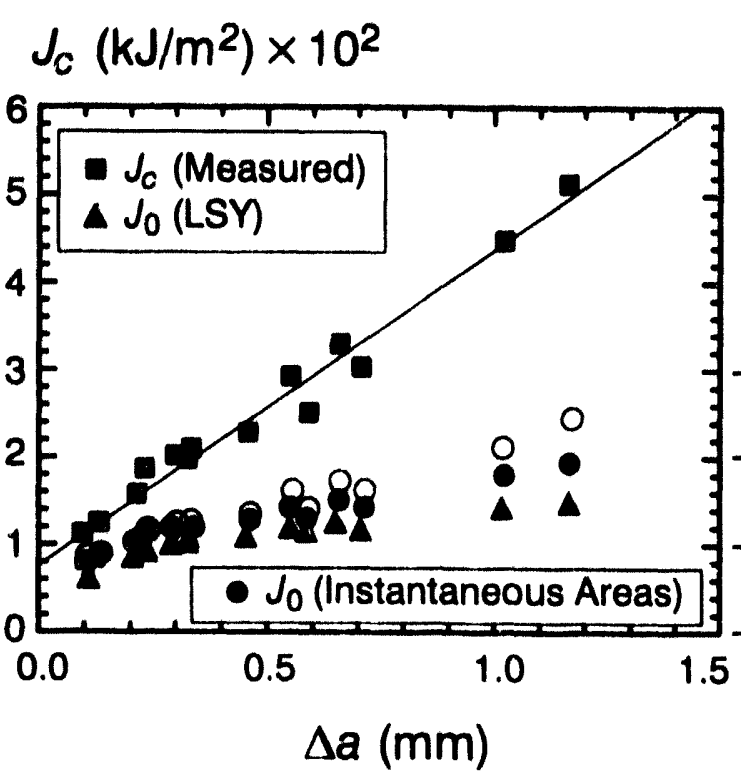

(a)

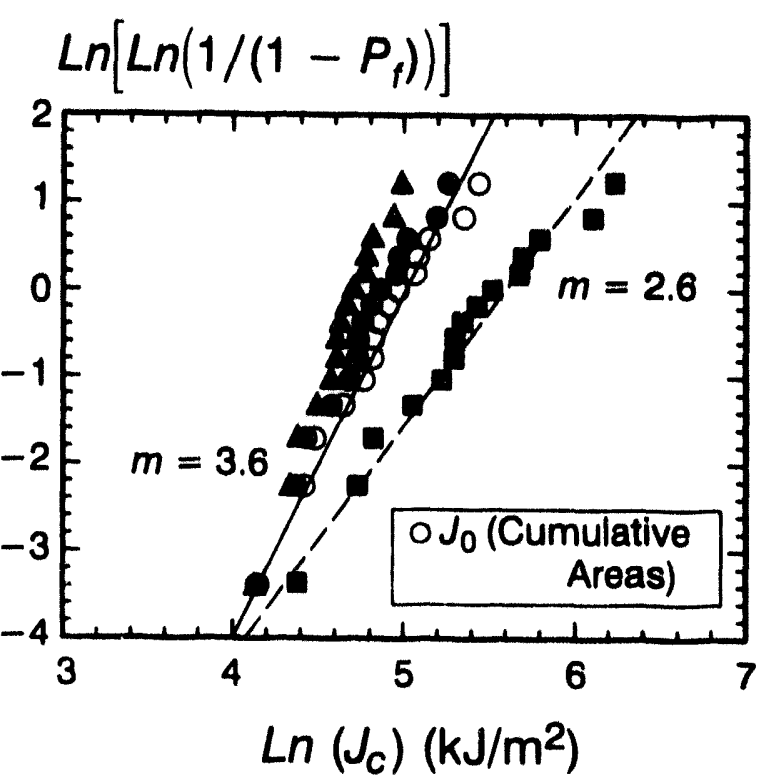

(b)

$$
\begin{gathered}
\text { A533B }\left(-15^{\circ}, 0^{\circ} \mathrm{C}\right), \text { McCabe }[17] \\
\mathrm{C}(\mathrm{T}), a / W=0.52, W=51 \mathrm{~mm}, \mathrm{~B}=25 \mathrm{~mm} \\
T_{J}=287 \quad J_{l c}=75 \mathrm{~kJ} / \mathrm{m}^{2} \quad \frac{E}{\sigma_{0}}=400 \\
n=10
\end{gathered}
$$

FIG. 17-Experimental $J_{R}-\Delta a$ curves and three-parameter Weibull distribution for A533B weld metal with corrections for effects of crack growth and large-scale yielding.

Figures 17 (b) and 18 (b) show uncorrected and corrected cleavage toughness values in the form of Weibull distributions for the A533B and A515 data sets. The Weibull diagrams show three sets of data: (1) the measured fracture toughness values $\left(J_{c}\right)$, shown as filled squares; (2) toughness values corrected only for constraint (loss) due to LSY, shown as filled triangles; and (3) toughness values corrected both for LSY and crack growth effects, shown as circles. The diagrams illustrate differences in the growth correction derived from instantaneous and cumulative areas for A533B; for A515 the instantaneous and cumulative corrections are identical and only the cumulative area result is shown.

To construct the Weibull diagrams, fracture probabilities for the ranked toughness values are computed using $F_{i}=(i-0.5) / N$. In these diagrams, straight lines represent the best fits to the distributions. The Weibull slopes of the dotted straight lines for the uncorrected distributions (2.4 and 2.6) are slightly larger than the theoretical slope of $m=2.0$ for toughness values expressed in terms of $J$. Similarly, slopes of the solid straight lines for the corrected distributions are larger as well $(m=3.1,3.6)$.

The trends of these first application of the growth correction model are encouraging with applications of the model to additional data sets required for verification, 


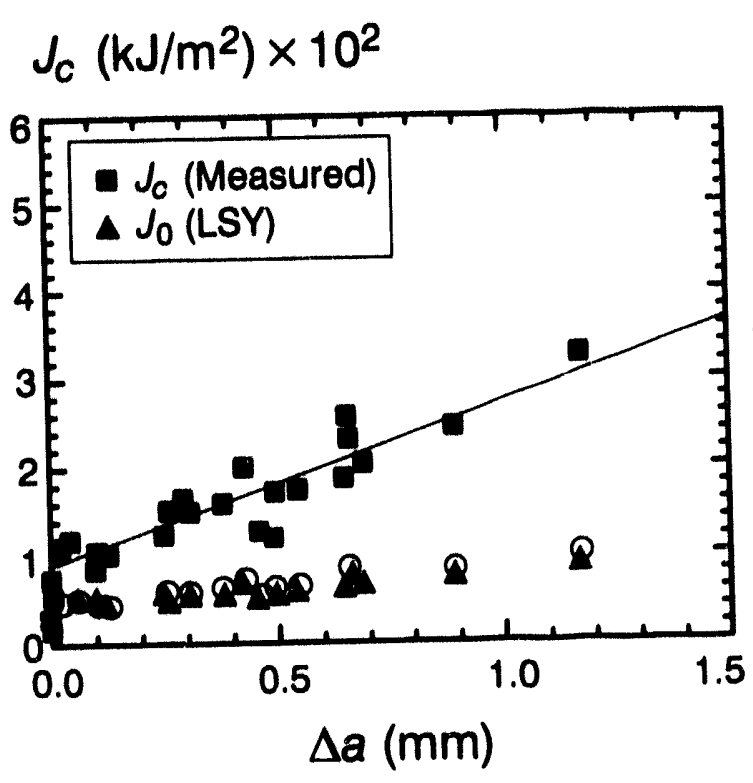

(a)

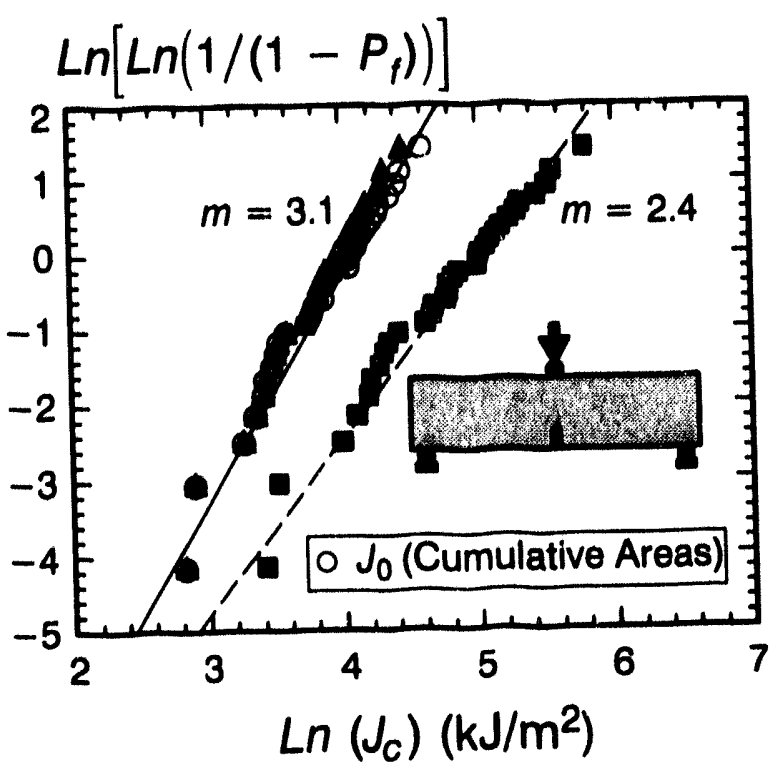

(b)

$$
\begin{gathered}
A 515\left(20^{\circ} \mathrm{C}\right), \text { Kirk, et al. [12] } \\
\operatorname{SE}(B), a / W=0.1, W=B=51 \mathrm{~mm} \\
\begin{array}{l}
T_{J}=420 \quad J_{l c}=88 \mathrm{~kJ} / \mathrm{m}^{2} \quad \frac{E}{\sigma_{0}}=700 \\
n=5
\end{array}
\end{gathered}
$$

FIG. 18-Experimental $J_{R}-\Delta a$ curves and three-parameter Weibull distribution for A515 with corrections for effects of crack growth and large-scale yielding.

especially data sets with moderate hardening and lower tearing modulus values relative to the blunting line slope.

\section{Conclusions}

The numerical investigation of small amounts of ductile crack growth in SE(B) specimens relevant to cleavage fracture described in this work supports the following conclusions:

1. The growing crack tip develops a macroscopically sharp opening profile and remains sharp for the maximum amount of growth considered in each combination of geometry and material properties. The crack-tip opening angle remains constant following the initial transient period of growth in the first 1-2 finite elements $\left(\Delta a \approx \delta_{I c}\right)$, and increases in proportion to increases in the tearing modulus.

2. During crack growth, $J$-values computed over domains very near the tip approach zero. For domains at distances from the current tip greater than $0.15-0.20 b_{0}, J$ bacomes path (domain) independent and agrees with $J$-values computed using the procedures described in ASTM E1152-87 (the deformation theory $J$ derived from growth corrected $\eta$ factors). 
3. Small amounts of crack growth can impact significantly the stress and deformation fields ahead of the extending tip. Compared to a stationary crack in an SE(B) loaded to the same $J$, crack growth may: elevate the opening mode stresses on the remaining ligament, elevate the stress triaxiality ahead of the tip, and increase the absolute size of principal stress contours enclosing the tip. The interaction crack growth with the degree of strain hardening, $J_{I c}, T_{J}, a / W$ and absolute specimen size is quite complex. The general effects of each parameter are: increased levels of strain hardening and larger tearing modulus values suppress the effects of crack growth (drive the growth constraint model towards the stationary crack model); large $J_{l c}$ values, small $a / W$ ratios and small specimen sizes magnify growth effects by severely lowering constraint at the onset of growth.

4. The principal stress contours ahead of the growing crack show a striking spatial similarity; while the absolute sizes of the contours scale nonlinearly with $J$, the angular variation in shape undergoes negligible changes during crack growth. These same observations about principal stress contours were made in earlier work that considered stationary cracks in SE(B) specimens.

5. The $J_{F B} / J_{0}$ ratios ( $F B$ denotes finite-sized specimens) predicted by the stressvolume constraint model including crack growth show a weak dependence on the principal stress contour $\left(\sigma_{1} / \sigma_{0}\right)$ selected for computation. For SE(B) specimens with $a / W=0.1$, crack growth restores a very weak dependence on $\sigma_{1} / \sigma_{0}$ relative to the much greater dependence on $\sigma_{1} / \sigma_{0}$ observed for a stationary crack at high $J_{F B}$-values (relative to specimen size). For $S E(B)$ specimens with $a / W=0.5$, the dependence on $\sigma_{1} / \sigma_{0}$ develops for both stationary and growing cracks when the global bending field impinges too strongly on the crack tip fields.

6. A relatively simple normalization procedure reduces the dependence of the constraint model on specific values of $J_{I c}$ - an important feature which increases the utility of limited numerical solutions. The gradient of the response (curve), $d J_{F b} / d J_{0}$, for the stationary crack model at $J=J_{I c}$ provides sufficient information to capture accurately $J_{I c}$ effects on the response during growth. Dependence on the tearing modulus cannot, be normalized; however, the tearing modulus effects appear amenable to simple curve fitting of the finite element results.

7. Cleavage fracture values for two different pressure vessel steels have been corrected for the effects of ductile tearing and large-scale yielding with the new constraint model. The constraint model which includes only large-scale yielding effects appears to overcorrect measured $J_{c}$-values in A533B that have some tearing prior to cleavage fracture $\left(J_{0}-\right.$ values are too small with only the LSY correction). In contrast, shallow notch specimens $(a / W=0.1)$ of a material (A515) with high strain hardening $(n=5)$ and a large tearing modulus $\left(T_{J}=400\right)$ exhibit essentially no increase in $J_{0}$-values predicted by the growth model. 


\section{References}

[1] Anderson, T. L., "A Combined Statistical and Constraint Model for the Ductile-Brittle Transition Region", ASTM STP 905, Vol-II, American Society for Testing and Materials, Philadelphia, pp. 563-583, 1989.

[2] Anderson, T.L., and Stienstra, D., "A Model to Predict the Sources and Magnitude of Scatter in Toughness Data in the Transition Region," Journal of Testing and Evaluation, Vol. 17, pp. 46-53, 1989.

[3] Anderson, T.L., and Dodds, R.H., "Specimen Size Requirements for Fracture Toughness Testing in the Ductile-Brittle Transition Region," Journal of Testing and Evaluation, Vol. 19, pp. 123-134, 1991.

[4] ASTM E1152-87, "Standard Test Method for Determining J-R Curves," American Society for Testing and Materials, Philadelphia, Pennsylvania, 1987.

[5] Bremin F. M., "A Local Criterion for Cleavage Fracture of a Nuclear Pressure Vessel Steel", Metallurgical Transactions A, V14A, pp. 2277-2287, 1983.

[6] Bruckner, A. and Munz, D., "Prediction of Failure Probabilities for Cleavage Fracture From The Scatter of Crack Geometry and of Fracture Tbughness Using the Weakest Link Model", Engineering Fracture Mechanics, V18, N2, pp. 359-375, 1983.

[7] Dodds, R.H., Anderson, T.L., and Kirk, M.T., "A Framework to Correlate $a / W$ Ratio Effects on Elastic-Plastic Fracture Toughness $\left(J_{c}\right)$," International Journal of Fracture, Vol. 48, pp. 1-22, 1991.

[8] Dodds, R.H., Shih, C.F., and Anderson, T.L., "Continuum and Micromechanics Treatment of Constraint in Fracture," International Journal of Fracture, Vol. 64, pp. 101-133, 1993.

[9] Dodds, R. H. and Tang, M., "Numerical Techniques to Model Ductile Crack Growth in Fracture Test Specimens," Engineering Fracture Mechanics, Vol. 46, No. 2, pp. 253-264, 1993.

[10] Healy, B.E. and Dodds, R..H., "A Large Strain Plasticity Model for Implicit Finite Element Analyses," Computational Mechanics, Vol. 9, No. 2, pp. 95-112, 1992.

[11] Ingham, T. et al., "Fracture Toughness in the Transition Regime for A533B Steel: Prediction of Large Specimen Results From Small Specimen Tests," Fracture Mechanics, ASTM STP 1020, American Society for Testing and Materials, Philadelphia, pp. 369-389, 1989.

[12] Kirk, M.T., Koppenhoeffer, K.C., and Shih, C.F., "Effect of Constraint on Specimen Dimensions Needed to Obtain Structurally Reievant Toughness Measures, " Constraint Effects in Fracture, ASTM STP 1171, E.M. Hackett, K.H. Schwalbe, and R.H. Dodds, Eds., American Society for Testing and Materials, Philadelphia, pp. 79-103, 1993.

[13] Kirk, M.T., and Dodds, R.H., "Approximate Techniques for Prediction of Size Effects on Cleavage Fracture Toughness," ASTM STP1207, J. Landes, D. McCabe and Boulet, Eds., Amrerican Society for Testing and Materials, Philadelphia, 1994.

[14] Kirk, M.T., and Dodds, R.H., "The Influence of Weld Strength Mismatch on Crack-Tip Constraint in Single Edge Notch Bend Specimens," International Journal of Fracture, Vol. 63, pp. 297-316, 1993.

[15] Koers, R. W. J., Krom, A. H.M., and Bakker, A., "Prediction of Cleavage Fracture in the Brittle to Ductile Transition Region of a Ferritic Steel," Constraint Effects in Fracture: Theory and Applications, ASTM STP1224, Mark Kirk and Ad Bakker Eds., Amrerican Society for Testing and Materials, Philadelphia, 1994.

[16] Landes J. D. and Shaffer, D. H., "Statistical Characterization of Fracture in the Transition Region," ASTM STP 700, pp. 368-382, 1980.

[17] McCabe, D. E. "A Comparison of Weibull and $\beta_{I c}$ in Transition Range Data," Fracture Mechanics: Twenty-Third National Symposium, ASTM STP 1189, Ed. R. Chona, American Society of Testing and Materials, Philadelphia, 1993, pp. 80-94.

[18] Moran, B., and Shih, C.F., "A General Treatment of Crack-Tip Contour Integrals," International Journal of Fracture, Vol. 35, pp. 295-310, 1987.

[19] O'Dowd, N.P., and Shih, C.F., "Family of Crack-Tip Fields Characterized by a Triaxiality Parameter: Part I - Structure of Fields," Journal of the Mechanics and Physics of Solids, Vol. 39., No. 8, pp. 989-1015, 1991. 
[20] O'Dowd, N.P., and Shih, C.F., "Family of Crack-Tip Fields Characterized by a Triaxiality Parameter: Part II - Fracture Applications," Journal of the Mechanics and Physics of Solids, Vol. 40, pp. 939-963, 1992.

[21] O'Dowd, N.P., Shih, C.F., and Dodds, R.H. "The Role of Geometry and Crack Growth on Constraint and Implications for Ductile/Brittle Fracture," to appear in Constraint Effects in Fracture, ASTM STP 1224, Mark Kirk and Ad Bakker Eds., American Society for Testing and Materials, Philadelphia, 1994.

[22] Parks, D.M., "Advances in Characterization of Elastic-Plastic Crack-Tip Fields," Topics in Fracture and Fatigue, Ed. A.S. Argon, Springer-Verlag, pp. 59-98, 1992.

[23] I.iu, N., and Drugan, W.J., "Finite Deformation Finite Element Analyses of Tensile Growing Cracks in Elastic-Plastic Material," International Journal of Fracture, Vol. 61, pp. 189-210, 1993.

[24] Ritchie, R. O., Knott J. F. and Rice, J. R., "On the relationship Between Critical Tensile Stress and fracture Toughness in Mild Steel", J. Mech. Phys. Solids, V21, pp. 395-410, 1973.

[25] Sham, T-L., "A Finite-element Study of the Asymptotic Near-tip Fields for Mode I Plane-strain Cracks Growing Stably in Elastic-Ideally Plastic Solids", in Elastic-Plastic Fracture, ASTM STP 803-I, American Society for Testing and Materials, Philadelphia, pp. 52-79, 1983.

[26] Shih, C.F., "J-Dominance under Plane Strain Fully Plastic Conditions: The Edge Crack Panel Subject to Combined Bending and Tension," International Journal of Fracture, Vol. 29, pp. 73-84, 1985.

[27] Sorem, W., Dodds, R. H., and Rolfe, S.T. "Effects of Crack Depth on Elastic-Plastic Fracture Toughness," International Journal for Fracture, Vol. 47, pp. 105-126, 1991

[28] Sorensen, E. P., "A Numerical Investigation of Plane Strain Stable Crack Growth Under Small-Scale Yielding Conditions,", in Elastic-Plastic Fracture, ASTM STP 668, American Society for Testing and Materials, Philadelphia, pp.151-174, 1979.

[29] Sumpter, J.D.G., and Forbes, A.T., "Constraint Based Analysis of Shallow Cracks in Mild Steel," Shallow Crack Fracture Mechanics, Toughness Tests and Applications, M.G. Dawes, Ed., Paper. No. 7, TWI, Cambridge, England, September 1992.

[30] Tang, M., Dodds, R.H. and Anderson, T.L., "Effects of Ductile Crack Growth on Constraint Models for Cleavage Fracture," SRS 585, UILU-ENG-94-2001, Department of Civil Engineering, University of Illinois at Urbana-Champaign, January 1994.

[31] Varias, A. G. and Shih, C. F., "Quasi-Static Crack Advance Under a Range of Constraints - Steady-State Fields Based on a Characteristic Length," Journal of Mechanics and Physics of Solids, V41, N5, pp. 835-861, 1993.

[32] Wallin, K., Saario, T., and Torronen, K., "Statistical Model for Carbide Induced Brittle Fracture in Steel," Metal Science, Vol. 18, pp. 13-16, 1984.

[33] Wallin, K., "The Size Effect in $K_{I c}$ Results," Engineering Fracture Mechanics, Vol. 22, No. 1, pp. 149-163, 1985.

[34] Wallin, K., "The Effect of Ductile Tearing on Cleavage Fracture Probability in Fracture Toughness Testing," Engineering Fracture Mechanics, Vol. 32, No. 4, pp. 523-531, 1989.

[35] Wallin, K., "Statistical Aspects of Constraint with Emphasis on Testing and Analysis of Laboratory Specimens in the Transition Region," Constraint Effects in Fracture, ASTM STP 1171, E.M. Hackett, K.H. Schwalbe, and R.H. Dodds, Eds., American Society for Testing and Materials, Philadelphia, pp. 264-288, 1993. 


\begin{tabular}{|c|c|}
\hline 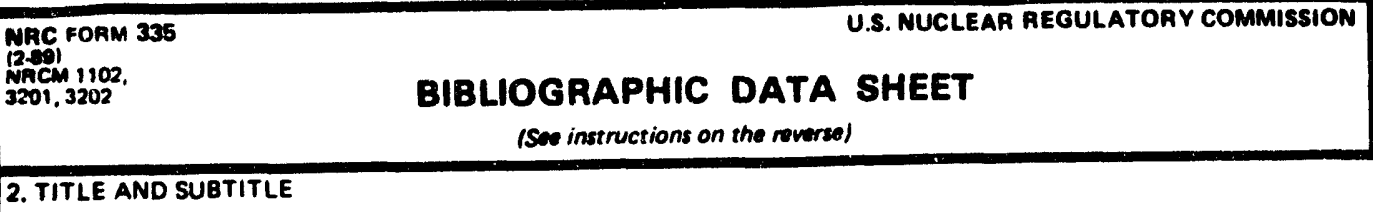 & 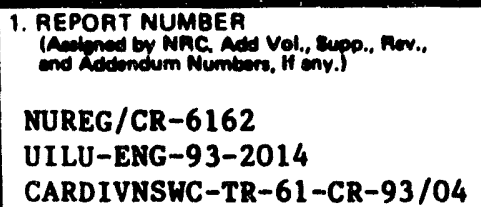 \\
\hline \multirow{3}{*}{$\begin{array}{l}\text { 2. TITLE AND SUBTITLE } \\
\text { Effects of Prior Ductile Tearing on Cleavage Fracture } \\
\text { Toughness in the Transition Region }\end{array}$} & 3. DATE REPORT PUBLISHED \\
\hline & \begin{tabular}{|l|r|} 
MONTH & VEAA \\
June & 1994 \\
\end{tabular} \\
\hline & $\begin{array}{l}\text { 4. FIN OR GRANT NUMBER } \\
\text { J6036 }\end{array}$ \\
\hline \multirow[t]{2}{*}{$\begin{array}{l}\text { 5. AUTHOR(S) } \\
\text { R. H. Dodds, Jr., M. Tang, University of I1linois } \\
\text { T. L. Anderson, Texas A\&M University }\end{array}$} & $\begin{array}{l}\text { 6. TYPE OF REPORT } \\
\text { Technica1 }\end{array}$ \\
\hline & $\begin{array}{l}\text { 7. PEAIOD COVERED (/Inc/usive Dates) } \\
\text { June } 92 \text { - Novenber } 93\end{array}$ \\
\hline
\end{tabular}

B. PERFORMING ORGANIZATION - NAME AND ADDRESS III NRC, provide Oivision, Oflice or Region, U.S. Nuclear Augulatory Commiascion, end malling eddress; if controctor, provide neme end meilng odores

University of I11inois

Department of Civil Engineering

205 North Mathews Ave.

Urbana, IL 61801
Texas A\&M University

Department of Mechanical

Engineering

College station, TX 77848
Under contract to:

Naval Surface

Warfare Center

Carderock Division Annapolis. MD 21402

9. SPONSORING ORGANIZATION - NAME AND ADDRESS IIf NRC, type 'Some es above"; if controcior, provide NRC Divsion, Orfice or Reglon, U.S. Nucteor Rogulatory Commission. and molling eddress.l

Division of Engineering

Office of Nuclear Regulatory Research

U.S. Nuclear Regulatory Commission

Washington, DC 20555-0001

10. SUPPLEMENTAAY NOTES

11. ABSTRACT (200 words or less)

Previous work by the authors described a micromechanis fracture model to correct measured $J_{c}$-values for the mechanistic effects of large-scale yielding. This new work extends the model to also include the influence of ductile crack extension prior to cleavage. Ductile crack extensions of 10-15 $x$ the initial crack tip opening displacement at initiation are considered in plane-strain, finite element computations. The finite element results demonstrate a significant elevation in crack-tip constraint due to macroscopic "sharpening" of the extending tip relative to the blunt tip at the initiation of growth. However this effect is offset partially by the additional plastic deformation associated with the increased applied $\mathrm{J}$ required to grow the crack. The initial a/ ratio, tearing modulus, strain hardening exponent and specimen size interact in a complex manner to define the evolving near-tip conditions for cleavage fracture. The paper explores development of the new model, provides necessary graphs and procedures for its application and demonstrates the effects of the model on fracture data sets for two pressure vessel steels (A533B and A515).

J-integral, scaling models, constraint, ductile-brittle crack growth

\begin{tabular}{l} 
Unlimited \\
14. SECURITY CLASSIFICATION \\
\hline This Pagel \\
Unclass if ied \\
(This Aeport \\
Unc lass if ied \\
15. NUMBER OF PAGES \\
16. PRICE
\end{tabular}



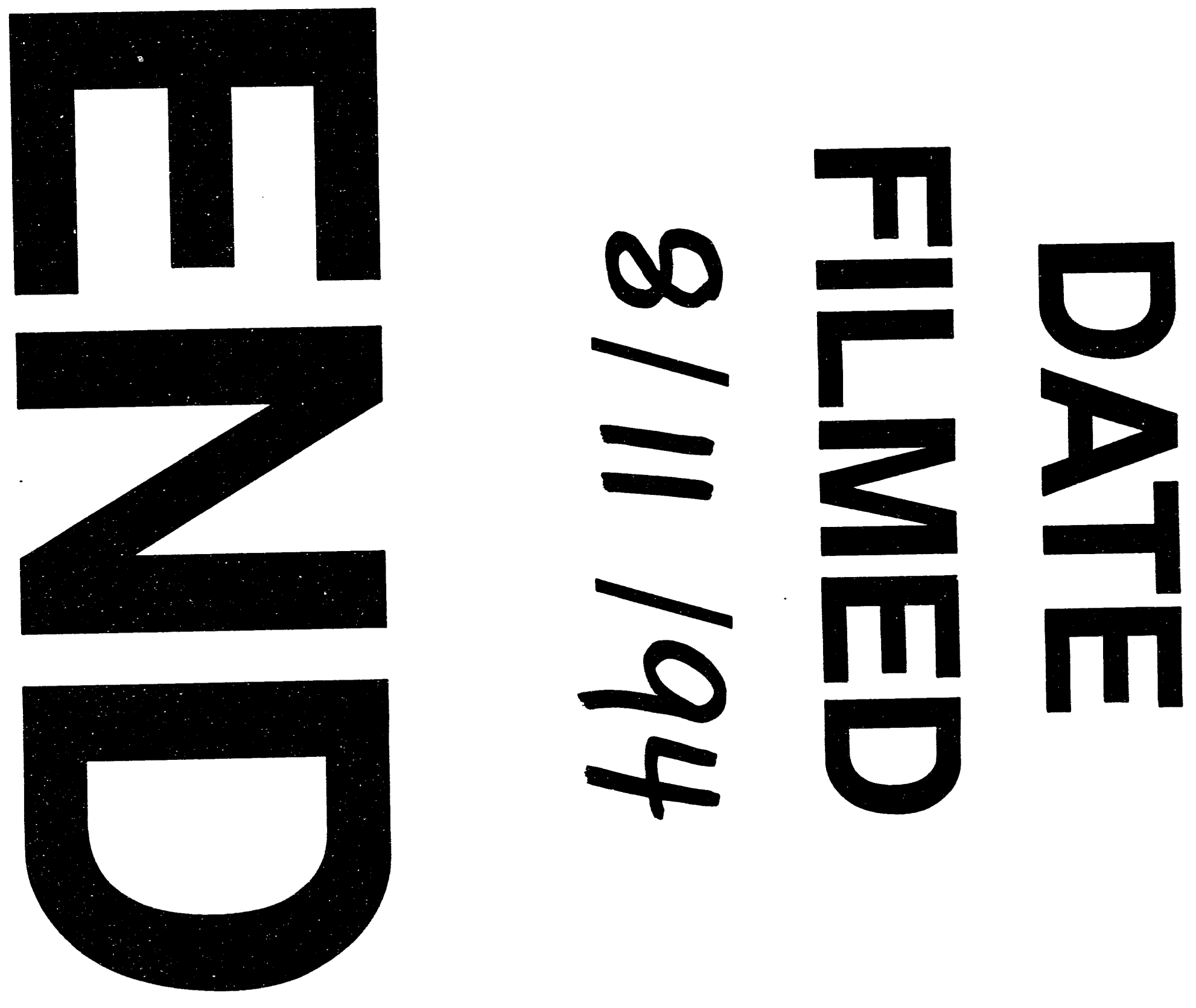
